\title{
Roles of the twin-arginine translocase and associated chaperones in the biogenesis of the electron transport chains of the human pathogen Campylobacter jejuni
}

Correspondence
David J. Kelly
d.kelly@sheffield.ac.uk

Received 22 June 2010

Revised 27 July 2010

Accepted 30 July 2010

\author{
Andrew Hitchcock, ${ }^{1} \dagger$ Stephen J. Hall, ${ }^{1} \dagger \ddagger$ Jonathan D. Myers, ${ }^{1} \S$ \\ Francis Mulholland, ${ }^{2}$ Michael A. Jones ${ }^{3}$ and David J. Kelly ${ }^{1}$ \\ ${ }^{1}$ Department of Molecular Biology and Biotechnology, The University of Sheffield, Firth Court, \\ Western Bank, Sheffield S10 2TN, UK \\ ${ }^{2}$ Institute of Food Research, Norwich Research Park, Colney Lane, Norwich NR4 7UA, UK \\ ${ }^{3}$ School of Veterinary Medicine and Science, The University of Nottingham, Sutton Bonnington, \\ Loughborough LE12 2RD, UK
}

†These authors contributed equally to this work.

łPresent address: Department of Chemical and Environmental Engineering, The University of Nottingham, University Park, Nottingham NG7 2RD, UK.

§Present address: Medlmmune Ltd, Granta Park, Cambridge CB1 6GH, UK.

Abbreviations: $\mathrm{BHI}$, brain heart infusion; $\mathrm{BHI}-\mathrm{FCS}, \mathrm{BHI}-$ fetal calf serum; $\mathrm{GADH}$, gluconate dehydrogenase; ICDH, isocitrate dehydrogenase; LB, Luria-Bertani; pmf, proton-motive force; MetSO, L-methionine sulfoxide; MHS, Mueller-Hinton broth supplemented with 20 mM L-serine; MTSO, methylene sulfoxide; NO, nitric oxide; $p$-PD, $p$-phenylenediamine; REMP, redox enzyme maturation protein; SNP, sodium nitroprusside; SPF, specific pathogen free; TAT, twin-arginine translocase; TMAO, trimethylamine $N$-oxide; TMPD, $N, N, N^{\prime}, N^{\prime}$-tetramethyl-p-phenylenediamine; TMSO, tetramethylene sulfoxide.

Two supplementary tables, showing primers used in this study and predicted substrates of the TAT system, and a supplementary figure, showing 2D gel electrophoresis of a selection of periplasmic proteins, are available with the online version of this paper.

\section{INTRODUCTION}

The Gram-negative epsilonproteobacterium Campylobacter jejuni is prevalent in the gut microbiota of many bird and animal species but is also an important human pathogen; ingestion of contaminated poultry is a common route of infection (Wagenaar et al., 2008). Consequently, C. jejuni is one of the most common causes of human enteric disease worldwide and is a major public health and economic burden (Jacobs-Reitsma et al., 2008). C. jejuni is microaerophilic and most strains are unable to grow well under conditions of full aeration or strict anaerobiosis (Sellars et al., 2002; Atack et al., 2008).

Elucidation of the major pathways of electron transport in C. jejuni has been achieved via a multi-faceted approach involving experimental testing of predictions from the genome sequences (for review see Kelly, 2008). For a small genome $(1.7 \mathrm{Mb})$ pathogen, a remarkably complex and 
branched electron transport system is present (see Fig. 1), which allows energy conservation and growth under a wide range of environmental conditions. Inorganic and organic compounds, including hydrogen, sulphite, formate, lactate and gluconate can be utilized as electron donors (Myers \& Kelly, 2005; Pajaniappan et al., 2008; Weerakoon et al., 2009; Thomas et al., 2010), and pathways to a number of alternative electron acceptors have been identified, permitting growth and energy conservation under extreme oxygen limitation, as might occur in the gut. Examples include fumarate (Weingarten et al., 2009; Guccione et al., 2010), nitrate and nitrite (Pittman et al., 2007), trimethylamine $N$-oxide (TMAO) and DMSO (Sellars et al., 2002; Weingarten et al., 2008). When C. jejuni is growing microaerobically with sufficient oxygen, electrons are transferred from menaquinone $\left(\mathrm{E}_{\mathrm{m}, 7}=-75 \mathrm{mV}\right)$ to one of two terminal oxidases, directly to the non-electrogenic quinol oxidase CioAB or via the proton-translocating cytochrome $b c_{1}$ complex and cytochrome $c$ to the $c b$-oxidase (Jackson et al., 2007).

A significant number of the C. jejuni electron transport enzymes are known or predicted to be localized in the periplasm (Kelly, 2008). The twin-arginine translocase (TAT) provides a unique periplasmic transport pathway that utilizes the proton motive force to move fully folded proteins across the cytoplasmic membrane (Berks, 1996; Berks et al., 2003). In bacteria, the TAT pathway can be involved in many cellular functions including respiration, cell envelope biogenesis, biofilm formation and metal homeostasis systems (Stanley et al., 2001; Ochsner et al., 2002; Ize et al., 2004; Joshi et al., 2010). In pathogens, the pleiotropic effects resulting from mutation of the TAT system can cause defects in virulence and host colonization

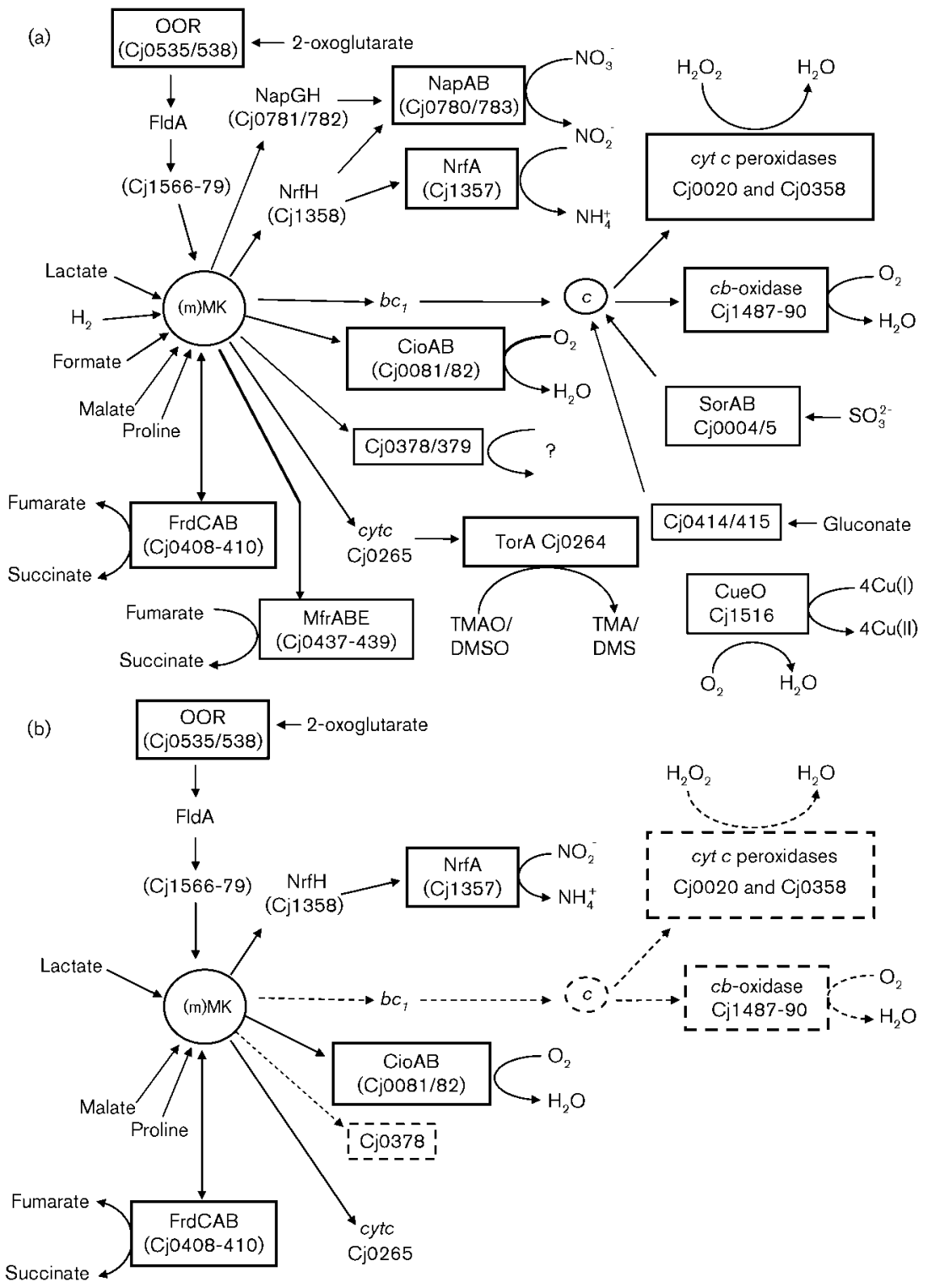

Fig. 1. Effect of tat $C$ mutation on the electron transport pathways in C. jejuni NCTC11168. The experimentally established or highly likely routes of electron transport are shown for the wild-type (a) and a tatC mutant (b). This study has experimentally demonstrated that a tatC mutant cannot utilize formate, hydrogen, sulphite or gluconate as electron donors and is unable to use TMAO or nitrate as an alternative electron acceptor to oxygen. In addition, MfrA, $\mathrm{MfrB}, \mathrm{Cj0379}$ and the multi-copper oxidase $\mathrm{CueO}$ are absent in the periplasm of a tatC mutant. Note that $\mathrm{NrfH}$ is not translocated by the TAT machinery despite having a TAT-like signal sequence. The dashed lines in (b) represent routes of electron transport expected to be lost in a tat $C$ mutant due to the suspected mislocalization of the PetA Rieske protein, which is part of the cytochrome $b c_{1}$ complex. Figure modified and updated from a figure by Kelly (2008). 
(Ochsner et al., 2002; De Buck et al., 2008; Rajashekara et al., 2009; Mickael et al., 2010), although these are often hard to ascribe to the mislocalization of a particular TAT substrate. Proteins bearing conserved twin-arginine residues in an N-terminal signal sequence motif S/TRRxFLK (Berks, 1996) are targeted to a membrane-integrated translocase complex consisting of three proteins: TatABC. TatB and $\mathrm{C}$ are believed to recognize the substrate, which is subsequently exported across the membrane via a pore formed by multiple TatA monomers (Gohlke et al., 2005; Palmer et al., 2005). C. jejuni contains homologues of tatA (cj1176c), tatB (cj0579c) and tatC (cj0578c) (Parkhill et al., 2000). Substrates for the TAT pathway include electron transport enzymes with complex redox cofactors which must be inserted in the cytoplasm, multi-subunit complexes which require assembly prior to export and proteins whose folding is incompatible with the Sec translocation system (Santini et al., 1998; Rodrigue et al., 1999; Bronstein et al., 2004).

For some complex bacterial TAT substrates, there is a preceding level of quality control present early on in their assembly. Regulation of transport is achieved by employment of dedicated cytoplasmic chaperone proteins that act as a 'proof reading' mechanism to coordinate protein folding and cofactor insertion with export (Sargent et al., 2002; Palmer et al., 2005). The substrates that require the action of these chaperones almost always contain a redox cofactor and TAT chaperones belong to a superfamily often referred to as redox enzyme maturation proteins (REMPs) (Turner et al., 2004). They are thought to function by binding to the signal peptide of cofactor-less immature apoproteins, hence blocking recognition by $\mathrm{TatC}$ and preventing premature export while they aid protein folding, cofactor biosynthesis and loading and docking of any partner subunits (Palmer et al., 2005; Genest et al., 2008, 2009; Li et al., 2010). Genes encoding REMPs are normally located in operons encoding the structural genes of the redox enzyme and chaperone protein function is specific to the redox enzyme in that particular operon; however, this is not always the case (Turner et al., 2004; Chan et al., 2009). The best studied Tat chaperones are DmsD (Oresnik et al., 2001; Ray et al., 2003) and TorD (Pommier et al., 1998; Ilbert et al., 2003; Jack et al., 2004), which act as REMPs for the DMSO and TMAO reductases, respectively, and NapD (Maillard et al., 2007), which functions with the Nap-type nitrate reductase. There is also evidence that general cytoplasmic chaperones, such as DnaK and SlyD, may have roles as Tat-signal-binding chaperones (Oresnik et al., 2001; Graubner et al., 2007). DnaK has been shown to have an important role in Tat targeting of the Escherichia coli multi-copper oxidase CueO (Graubner et al., 2007), while SlyD may participate in the assembly of $\mathrm{Ni}-\mathrm{Fe}$ hydrogenases in E. coli (Zhang et al., 2005) and urease in Helicobacter pylori (Stingl et al., 2008).

Only two proteins, alkaline phosphatase (Cj0145) and the nitrate reductase NapA subunit have thus far been shown to be TAT substrates in C. jejuni (strain 81116; van Mourik et al., 2008). A recent study of the TAT system in C. jejuni 81-176 (Rajashekara et al., 2009) has shown that a tatC null mutant exhibits an increased sensitivity to antimicrobial compounds and has defects in biofilm formation, motility and flagellation. The ability of this mutant to survive under osmotic shock and oxidative and nutrient stress was also reduced, as was its capability to colonize chickens. However, the colonization defect cannot be solely ascribed to the loss of the TAT system, as changes in motility/ flagellation can also result in reduced virulence and colonization (Nachamkin et al., 1993; Hendrixson \& DiRita, 2004) and it is possible that at least some of the diverse phenotypes observed in the mutant are due to indirect secondary effects on global cellular processes, rather than specific absences of TAT substrates in the periplasm (Bronstein et al., 2004; Rajashekara et al., 2009).

In this study we have identified, by proteomics and activity measurements, the majority of the proteins that are predicted to be exported via the TAT pathway in the NCTC11168 wild-type strain, an isogenic tat $C$ mutant and a tatC/tatC ${ }^{+}$complemented strain. This has allowed a mechanistic explanation of specific growth phenotypes resulting from loss of the TAT system. The results clearly reveal the key role played by the TAT system in the assembly of the electron transport chains, particularly regarding export of the novel tungstoenzyme formate dehydrogenase and the molybdo-enzymes sulphite oxidase, nitrate reductase, TMAO/DMSO reductase and Cj0379 (see Fig. 1). The last protein is the only TAT-transported molybdoenzyme in C. jejuni with an unknown function; based on mutant studies, we suggest a possible role in periplasmic nitrosative stress resistance. Finally, the role and specificity of a homologue of the TorD chaperone has been investigated and shown to be essential only for formate dehydrogenase activity.

\section{METHODS}

Bacterial strains, media and culture conditions. $C$. jejuni strains NCTC11168 and the hypermotile variant $11168 \mathrm{H}$ (Karlyshev et al., 2002) were routinely cultured at $37{ }^{\circ} \mathrm{C}$ under microaerobic conditions $\left[10 \%(\mathrm{v} / \mathrm{v}) \mathrm{O}_{2}, 5 \%(\mathrm{v} / \mathrm{v}) \mathrm{CO}_{2}\right.$ and $\left.85 \%(\mathrm{v} / \mathrm{v}) \mathrm{N}_{2}\right]$ in a MACS growth cabinet (Don Whitley Scientific) on Columbia agar containing $5 \%(\mathrm{v} / \mathrm{v})$ lysed horse blood and $10 \mu \mathrm{g} \mathrm{ml}^{-1}$ each of amphotericin $\mathrm{B}$ and vancomycin. Where appropriate, kanamycin or chloramphenicol was added at a final concentration of $30 \mu \mathrm{g} \mathrm{ml}^{-1}$. Liquid cultures of C. jejuni for enzyme assays were routinely grown in MuellerHinton broth (Oxoid) supplemented with $20 \mathrm{mM}$ L-serine (MHS) under standard microaerobic conditions (gas concentrations as above), with $50-100 \mathrm{ml}$ medium contained in $250 \mathrm{ml}$ conical flasks with continuous orbital shaking at 180 r.p.m. Liquid cultures of $C$. jejuni for growth curves under oxygen-limited conditions were grown in brain heart infusion (BHI) broth supplemented with $5 \%(\mathrm{v} / \mathrm{v})$ fetal calf serum (BHI-FCS). The gas atmosphere was the same as described for standard microaerobic conditions but the diffusion of oxygen was restricted by using $500 \mathrm{ml}$ medium contained in a $500 \mathrm{ml}$ conical flask with no shaking, as described previously (Sellars et al., 2002; Guccione et al., 2010). Electron acceptors were added from filtersterilized stock solutions to a final concentration of $20 \mathrm{mM}$. Cultures were maintained in the MACS-VA500 incubator and growth was 
monitored by measuring $\mathrm{OD}_{600}$. Growth curves shown are representative of single experiments but all growth experiments were repeated three times with similar results. E. coli $\mathrm{DH} 5 \alpha$ was cultured in Luria-Bertani (LB) broth or agar supplemented with appropriate antibiotics at $37^{\circ} \mathrm{C}$.

DNA isolation, manipulation and construction of mutants. $C$. jejuni NCTC11168 chromosomal DNA was extracted by using the wizard genomic DNA purification kit (Promega). Standard techniques were employed for the cloning, transformation, preparation and restriction analysis of plasmid DNA from E. coli (Sambrook et al., 1989). Mutants were constructed by insertion of an antibiotic resistance gene in the same transcriptional orientation as the gene of interest. Accuzyme (Bioline) proof reading DNA polymerase was used for all PCRs and the primers used are detailed in Supplementary Table S1, available with the online version of this paper. The tatC gene (cj0578c) was amplified from genomic DNA using the specific primers tatC-F and tatC-R. The resulting 899 bp fragment was cloned into pGEM3Zf $(-)$ (Promega). The kanamycin resistance (kan) cassette from Campylobacter coli (Wang \& Taylor, 1990), derived by PCR from plasmid pJMK30 (van Vliet et al., 1998) using primers kan$\mathrm{F}$ and kan-R, was cloned into the unique restriction site $B s a \mathrm{BI}$ in $t a t C$ to produce plasmid ptatCkan. Correct insertion of the antibiotic resistance cassette into the target gene was confirmed by PCR. For inactivation of $c j 0379 c$, PCR primers cj0379c-F and cj0379c-R were used to amplify a $1.4 \mathrm{~kb}$ product containing the $c j 0379 \mathrm{c}$ ORF, which was cloned into pGEMT-easy (Promega) to form pcj0379. A $1.7 \mathrm{~kb}$ SmaI fragment containing the kan resistance gene from pJMK30 was then cloned into a unique $K p n I$ site in $c j 0379 c$ to form pcj0379kan. The $c j 1514 c$ (torD homologue) gene and 400 bp upstream flanking DNA was amplified using primers torD-F and torD-R. The $1.1 \mathrm{~kb}$ PCR product was cloned into the EcoRI site of pGEM3Zf $(-)$ and transformants were recovered as above. The kan cassette from pJMK30 was blunt end cloned into the unique EcoRV site in cj1514 to produce plasmid ptorDkan. Plasmids ptatCkan, pcj0379kan and ptorDkan were transformed by electroporation into $C$. jejuni NCTC11168 and transformants were selected using Columbia blood agar plates supplemented with kanamycin $\left(30 \mu \mathrm{g} \mathrm{ml}^{-1}\right.$ final concentration). pcj0379kan was also transformed into NCTC11168H for chicken colonization studies (see below). Gene-specific primers were used to confirm allelic exchange by double crossover in each of the mutants.

Construction of complemented strains. For construction of a complemented $t a t C$ strain, the $t a t C$ gene plus the upstream ribosomebinding site was amplified by PCR using primers tatC-F and tatC-R and cloned into the XbaI site of the vector pRRC (Karlyshev \& Wren, 2005) that integrates into one of the three rRNA loci in C. jejuni, to produce $\mathrm{pCtat} C$. This was then transformed into the tat $C$ mutant strain of C. jejuni by electroporation and selection on Columbia blood agar plates containing both chloramphenicol and kanamycin. Confirmation of the insertion of the complementation cassette at one of the rRNA loci was carried out by PCR using primers tatC-F and C-seq-R. For complementation of torD, the ORF plus upstream promoter and ribosome-binding site was amplified by PCR using the primers torDcomp-F and torDcomp-R. The resulting fragment was digested with BsmBI and cloned into pC46 (Gaskin et al., 2007) to create the vector pCtor D. This was transformed into the tor $D$ mutant strain as above. This complementation construct integrates at the cj0046 pseudogene locus and the presence of both a wild-type and mutated copy of torD was confirmed by PCR with torD-gene-specific primers.

Construction of TAT peptide-TorA fusion strains. The TorAencoding gene $c j 0264 c$ was amplified by PCR so that the N-terminal signal sequence of the protein was removed. This fragment was digested with $\mathrm{XbaI}$ and cloned into similarly digested pRRC vector
(Karlyshev \& Wren, 2005) to produce pSJHX. PCR products encoding the signal peptide of the putative translocated protein Cj0414 and the torA signal peptide (positive control), were digested with $A g e I$ and NarI and cloned into similarly digested pSJHX to produce in-frame signal peptide-torA fusions. The plasmid pSJHX carries a chloramphenicol resistance gene with its own promoter, which acts as the selection marker and drives expression of the signal peptide-torA fusion in vivo. The fusion plasmids were electroporated into C. jejuni strain SJH100, which carries an insertional mutation in the chromosomal torA gene (Sellars et al., 2002), and the tatC mutant.

Enzyme assays. All assays were performed at $37{ }^{\circ} \mathrm{C}$ using a Shimadzu UV-2401PC spectrophotometer. Methyl/benzyl-viologenlinked reductase assays were carried out with intact cells or periplasmic extracts in a $1 \mathrm{ml}$ assay mixture contained in a screw top glass cuvette with a silicone seal to prevent gas exchange (Guccione et al., 2010). All buffers and solutions were made anaerobic by sparging with oxygen-free nitrogen. The final assay mixture contained $25 \mathrm{mM}$ sodium phosphate buffer, $\mathrm{pH} 7$, (whole cells) or $10 \mathrm{mM}$ Tris/HCl buffer, $\mathrm{pH} 7.5$, (periplasm) with $1 \mathrm{mM}$ methyl viologen (TMAO and nitrate reduction) or benzyl viologen (fumarate reduction) and $5 \mathrm{mM}$ electron acceptor (TMAO, sodium nitrate or sodium fumarate). Cells or periplasm were added to the buffer plus viologen mixture, sparged with oxygen-free nitrogen, and aliquots of freshly prepared sodium dithionite solution were injected into the cuvette until a steady absorbance at 585 or $578 \mathrm{~nm}$ was achieved (for methyl and benzyl viologen, respectively). The assay was initiated by the injection of an anaerobic solution of electron acceptor and the absorbance decrease was recorded. For hydrogenase activity, the buffer/methyl viologen assay mixture was saturated with hydrogen gas and the assay was initiated by the addition of cells. Formate dehydrogenase assays were carried out as for reductase assays but the sparged cell/buffer/benzyl viologen mixture was not reduced with dithionite prior to the assay being started by the addition of an anaerobic solution of $10 \mathrm{mM}$ sodium formate. Specific activities for all substrates were calculated using an absorption coefficient for methyl viologen of $11.8 \mathrm{mM}^{-1} \mathrm{~cm}^{-1}$ at $585 \mathrm{~nm}$ and for benzyl viologen of $8.6 \mathrm{mM}^{-1} \mathrm{~cm}^{-1}$ at $578 \mathrm{~nm}$. Phenoloxidase assays were carried out on whole cells as described previously (Hall et al., 2008). The $1 \mathrm{ml}$ assay volume consisted of $25 \mathrm{mM}$ sodium acetate buffer pH 5.7 and $100 \mu \mathrm{l}$ of cells. Assays were started by addition of the chromogenic substrate $p$-phenylenediamine $(p$-PD) to a final concentration of $10 \mathrm{mM}$ and rates were recorded at $487 \mathrm{~nm}$. Specific activities were calculated using an absorption coefficient for $p$-PD of $14.7 \mathrm{mM}^{-1} \mathrm{~cm}^{-1}$ at $487 \mathrm{~nm}$ (Hall et al., 2008). Protein concentrations of cell suspensions were determined using the method described by Markwell et al. (1978).

Disc diffusion assays and dose-response curves. For disc diffusion assays, $100 \mathrm{ml}$ BHI-FCS liquid cultures were grown microaerobically with shaking for $16 \mathrm{~h}$ at $37^{\circ} \mathrm{C}$. The final $\mathrm{OD}_{600}$ was adjusted to 0.1 by the addition of fresh BHI broth and the suspension was added to molten Mueller-Hinton agar at $50{ }^{\circ} \mathrm{C}$, and plates were poured. Inhibition zones surrounding $8 \mathrm{~mm}$ diameter, sterile filter discs containing $5 \mu 100 \mathrm{mM}$ sodium nitroprusside were measured after 2 days microaerobic incubation at $37{ }^{\circ} \mathrm{C}(12$ replicate plates per strain). For dose-response curves, $100 \mathrm{ml}$ BHI-FCS cultures of the strains to be tested were grown for $3 \mathrm{~h}$ after inoculation to an $\mathrm{OD}_{600} 0.1$ with an overnight starter culture. The $\mathrm{OD}_{600}$ of the cultures were equalized to 0.1 by dilution with fresh sterile BHI. Three replicates of $150 \mu \mathrm{l}$ each culture were added to wells in a sterile 96-well microtest plate (Costar). Sodium nitroprusside (0$20 \mathrm{mM}$ ) was added to each of the replicate cultures to make the final volume $200 \mu \mathrm{l}$. The microtest plates were then incubated in a microaerobic atmosphere at $37^{\circ} \mathrm{C}$ for $1 \mathrm{~h}$. After incubation, the cultures were serially diluted with sterile BHI and plated onto 
Mueller-Hinton agar plates. The agar plates were incubated in a microaerobic atmosphere at $37^{\circ} \mathrm{C}$ for $3-4$ days before counting the c.f.u.

Measurement of respiration rates and nitric oxide (NO) consumption. Substrate-dependent oxygen respiration rates were determined as described previously (Myers \& Kelly, 2005; Thomas et al., 2010), by measuring the change in dissolved oxygen concentration of cell suspensions in a Clark-type oxygen electrode, linked to a chart recorder and calibrated using air-saturated $25 \mathrm{mM}$ phosphate buffer ( $\mathrm{pH} 7.5)\left(220 \mathrm{nmol}\right.$ dissolved $\mathrm{O}_{2} \mathrm{ml}^{-1}$ at $\left.37^{\circ} \mathrm{C}\right)$. The cell suspension was maintained at $37{ }^{\circ} \mathrm{C}$ and stirred at a constant rate. Substrates $[0.5 \mathrm{mM}$ sodium sulphite, $10 \mathrm{mM}$ organic acids or $0.25 \mathrm{mM} N, N, N^{\prime}, N^{\prime}$-tetramethyl-p-phenylenediamine (TMPD) plus $1 \mathrm{mM}$ ascorbic acid] were added by injection through a fine central pore in the airtight plug. Consumption of NO by intact cells of the wild-type and $c j 0379 c$ mutant was measured as described by Pittman et al. (2007) in a similar oxygen electrode as above, but with the reaction-chamber plug adapted with a hole to allow the additional use of a NO-specific electrode connected to an ISO-NO Mark II nitric oxide meter (World Precision Instruments). Both electrodes were linked to a chart recorder and the oxygen electrode was calibrated using air-saturated water as above. The NO electrode was calibrated by additions from a saturated solution of NO gas in anaerobic water $(1.8 \mathrm{mM})$. Sodium formate (5 $\mathrm{mM}$ final concentration) was added to the cell suspension as an electron donor. The reaction chamber was allowed to become anaerobic by the consumption of oxygen by the cells, after which $4.5 \mu \mathrm{M}$ NO solution was injected and the resulting response was recorded by the NO electrode. The NO electrode trace was measured for peak height and length of time for $50 \%$ degradation to occur.

Determination of nitrite reduction in cell suspensions. Cells were harvested from $150 \mathrm{ml}$ overnight MHS cultures by centrifugation, washed twice, and finally resuspended in $3 \mathrm{ml} 25 \mathrm{mM}$ phosphate buffer ( $\mathrm{pH} 7.5$ ) to approximately $6 \mathrm{mg}$ total cell protein $\mathrm{ml}^{-1}$. This was added directly to the chamber of a Clark-type oxygen electrode, which was set up as above. Cells were provided with $20 \mathrm{mM}$ sodium succinate as an electron donor and allowed to respire until a zero oxygen baseline was reached. After $5 \mathrm{~min}, 3 \mathrm{mM}$ sodium nitrite was added to the chamber as the electron acceptor, $50 \mu \mathrm{l}$ samples were taken at time intervals, immediately microcentrifuged and the supernatants were stored at $-20{ }^{\circ} \mathrm{C}$. Diluted culture supernatants $(50 \mu \mathrm{l})$ were added to $850 \mu \mathrm{l}$ of $1 \%$ (w/v) sulphanilamide dissolved in $1 \mathrm{M} \mathrm{HCl}$ and $100 \mu \mathrm{l} 0.02 \%$ (w/v) naphthylethylenediamine (Pittman et al., 2007). After $15 \mathrm{~min}$, the absorbance at $540 \mathrm{~nm}$ was measured, and nitrite concentrations were determined by reference to a standard curve.

Cellular fractionation of C. jejuni. For 2D gel proteomic analysis, an osmotic shock method developed previously for C. jejuni was used (Myers \& Kelly, 2005; Guccione et al. 2010). For rapid determination of selected enzyme activities, periplasm and cytoplasm were isolated by polymyxin B treatment of whole cells, as described previously (Sommerlad \& Hendrixson, 2007; Atack et al., 2008). Contamination of the periplasm by cytoplasmic proteins was assayed using cytochrome $c$ content as the periplasmic marker and isocitrate dehydrogenase (ICDH) activity as the cytoplasmic marker, using the assays described by Myers \& Kelly (2005). These assays showed that with either fractionation method, the periplasm contained about $10 \%$ of the total ICDH activity.

1D and 2D gel electrophoresis, immunoblotting and proteomics. Proteins were separated by standard SDS-PAGE using the Mini-PROTEAN 3 apparatus (Bio-Rad) on $10 \%$ (w/v) acrylamide gels, and immunoblotting with anti-MfrA antibodies, carried out exactly as described previously (Guccione et al., 2010). Periplasmic fractions were analysed by $2 \mathrm{D}$ gel electrophoresis using the protocol described in our previous work (Leon-Kempis et al., 2006; Guccione et al., 2010). Proteins were stained with SYPRO Ruby (Bio-Rad) and the gels were imaged using the Pharos FX + Molecular Imager with Quantity One imaging software (Bio-Rad). Protein spots were excised from the gel using the ProPick excision robot (Genomic Solutions) and in-gel tryptic digestion was performed as described by Holmes et al. (2005). Tryptic digests were analysed using an Ultraflex MALDITOF instrument (Bruker). Proteins were identified by using the Protein Mass Fingerprint technique using the MASCOT search tool (Matrix Science; http://matrixscience.com). Mowse scores greater than 55 were statistically significant at $P<0.05$.

Chicken colonization studies. Chicken colonization studies were performed under licence at the Institute of Animal Health, Compton, Berkshire, UK. Specific pathogen free (SPF) Rhode Island Red chicks were obtained on the day of hatching from the Poultry Production unit, Institute for Animal Health, Compton, UK. All birds were inoculated orally with $0.1 \mathrm{ml}$ Campylobacter-free adult gut flora preparation, produced by static culture of $1 \mathrm{~g}$ caecal contents obtained from a freshly killed 50-week-old SPF chicken in $10 \mathrm{ml} \mathrm{LB}$ broth for $23 \mathrm{~h}$ at $37^{\circ} \mathrm{C}$. Inoculated birds were housed and nourished on a vegetable-based diet (Special Diets Services) under appropriate SPF conditions until 3 weeks of age when they where used for the colonization trial. Groups of 243 -week-old birds were inoculated orally with $0.1 \mathrm{ml}$ culture containing $10^{7}$ c.f.u. of the desired Campylobacter strain. Unidirectional sterile swabs of the birds cloacal were taken and faecal secretion was tested by direct count and enrichment count as follows: cloacal swabs were taken at weekly intervals and were mixed into $1 \mathrm{ml}$ modified Exeter broth (Baylis et al., 2000). For direct counts, swabs were streaked onto Campylobacter blood-free selective agar (CCDA and CM739 containing selective supplement SR155; Oxoid) and colony counts were scored positive or negative after 2 days of incubation. Swabs were then placed back into the enrichment media (modified Exeter broth) and were incubated under microaerobic conditions at $37{ }^{\circ} \mathrm{C}$. After 2 days, the enrichment cultures were checked for Campylobacter by plating on Campylobacter blood-free agar. These were scored as positive or negative results and referred to as enrichment counts. At 7 weeks post-inoculation, the birds were killed and the average post-mortem c.f.u. $\mathrm{g}^{-1}$ was determined from the caecal contents counts of three and five birds from the groups inoculated with the $11168 \mathrm{H}$ and cj0379cH strains, respectively. Samples were diluted in PBS and were immediately plated on Campylobacter blood-free agar.

\section{RESULTS}

\section{Predicted TAT substrate proteins in C. jejuni NCTC11168}

Supplementary Table S2 shows the proteins identified as potential TAT pathway targets in the C. jejuni NTC11168 genome based on the results from the prediction programs TATFIND v1.4 (Rose et al., 2002; Dilks et al., 2003) and TatP v1.0 (Bendtsen et al., 2005) when run on all the translated proteins from the complete genome sequence. The results are largely in agreement with those of Rajashekara et al. (2009) in C. jejuni strain 81-176, except that we excluded Cj0692 which has a very poor TAT motif (LRRRFKK) more than 40 residues from the $\mathrm{N}$ terminus. Despite negative predictions from both TATFIND and TatP (seemingly due to lack of a cleavage site), we considered the electron transfer proteins $\mathrm{NapH}$ and $\mathrm{NrfH}$ as examples of 
possible uncleaved, membrane-bound TAT substrates due to the presence of an appropriately placed arg-arg (RR) containing N-terminal motif. This would be similar to the iron-sulphur cluster containing Rieske protein (Cj1186), a subunit of the cytochrome $b c_{1}$ complex that is predicted to be anchored to the membrane on the periplasmic side by an uncleaved TAT signal peptide. The prediction programs disagreed in the case of two proteins, alkaline phosphatase (Cj0145) and hydrogenase (Cj1267); the former has been shown experimentally to be a TAT substrate (van Mourik et al., 2008). Although TAT substrates containing a twin-arginine motif are most common, proteins with a lys-arg (KR) rather than RR pair have been identified (Hinsley et al., 2001). A further four proteins with a KR motif are present in strain NCTC11168, including a MurF (UDP- $N$-acetylmuramoyl-L-alanyl-Dglutamyl-meso-2,6-diaminopimeloyl-D-Ala-D-Ala synthetase) homologue, a protease and a lipoprotein. These were not investigated further in this study as they are not predicted to be involved in electron transport. Fig. 1(a) highlights those predicted TAT substrate proteins that play a crucial role in the electron transport pathways of $C$. jejuni. The TAT substrate predictions suggest that $C$. jejuni relies heavily on the TAT system for the efficient biogenesis and assembly of respiratory pathways and that the respiratory capabilities of a strain lacking this pathway are likely to be severely compromised.

\section{Proteomic analysis of a tatC mutant}

In order to obtain an initial view of the effects of the loss of the TAT system on the periplasmic protein complement of C. jejuni, periplasmic fractions from wild-type and tatC mutant cells grown under microaerobic conditions to exponential and stationary phase were separated by $2 \mathrm{D}$ gel electrophoresis followed by SYPRO Ruby staining (Fig. 2). Mass spectrometry analysis of spot picks (Mowse scores $>55$ ) positively identified a selection of proteins (see Fig. 2 and Supplementary Fig. S1). Periplasmic proteins without a TAT motif (Supplementary Fig. S1) could always be detected in both wild-type and mutant samples, although there was some variation in their abundance on the gels, despite equal protein loadings. However, a number of possible TAT-transported substrates were consistently less abundant or completely absent in the tatC mutant periplasm compared with the wild-type. The clearest example in exponential phase samples was $\mathrm{HydB}$, the large subunit of the hydrogenase (compare Fig. 2a and b). This does not have its own TAT sequence but is likely to be translocated along with the TAT signal-containing small subunit, HydA, which was also identified on the gel run with wild-type proteins (Fig. 2a) but was absent on the gel of the tatC mutant (Fig. 2b). Both subunits of the gluconate dehydrogenase Cj0414 and Cj0415 were clearly identified as being absent in the tat $C$ mutant periplasm; only Cj0414 has a TAT signal sequence, suggesting cotranslocation of Cj0415. The periplasmic subunits of the Mfr fumarate reductase (MfrA and MfrB) are highly induced by oxygen limitation (Guccione et al., 2010) and were only identified in wild-type stationary phase periplasm (Fig. 2c). Of the periplasmic molybdoenzymes in $C$. jejuni NCTC11168, three (NapA, TorA and Cj0379) were identified as being present in the wild-type and absent in the tatC mutant periplasm (Fig. 2a and c), consistent with their translocation in a TAT-dependent manner.

\section{A tatC mutant has both aerobic and oxygen- limited growth defects}

Fig. 3 shows the growth characteristsics of the wild-type strain, the tat $C$ mutant and the mutant complemented with the wild-type $t a t C$ gene (a $t a t C / t a t C^{+}$merodiploid). Under microaerobic conditions in complex media, there was a clear reduction in the growth rate of the mutant and also in the final cell yield achieved. This indicates that the tat $C$ mutation reduces the energetic efficiency of aerobic growth. Under oxygen-limited conditions with the alternative electron acceptors TMAO (Fig. 3b) or nitrate (Fig. 3c) the mutant showed a severe growth defect that would be consistent with a failure of export of the molybdoenzyme subunits of the TMAO reductase (TorA, Cj0264) and nitrate reductase (NapA) observed in Fig. 2. In each case, the mutant growth phenotypes were restored to the wildtype characteristics in the tatC/tatC$C^{+}$merodiploid complemented strain.

\section{Verification of the TAT dependence of specific electron transport proteins}

To confirm that the predicted TAT substrates are periplasmically localized via their TAT signal sequences, a combination of direct enzyme activity and respiration rate measurements were carried out in the isogenic set of wildtype, $\operatorname{tat} C$ and $\operatorname{tat} C / \operatorname{tat}^{+}$strains. Table 1 shows that the wild-type and complemented strains were able to aerobically respire sulphite at an approximately equal rate, but sulphite-dependent oxygen respiration was undetectable in the tatC mutant. That this loss of activity was due to mislocalization of the sulphite oxidase subunit SorA and not due to a disturbance of electron flux to cytochrome $c$ oxidase, was confirmed by rates of oxygen consumption with TMPD/ascorbic acid (which donates electrons directly at the level of periplasmic cytochrome $c$ into the $c b$-type cytochrome $c$ oxidase) being similar in both the mutant and parent strain $\left[\sim 200 \mathrm{nmol} \mathrm{O}_{2} \min ^{-1}\right.$ (mg protein) $\left.{ }^{-1}\right]$.

To assay TMAO/DMSO reductase, periplasmic fumarate reductase (Mfr; mis-annotated as succcinate dehydrogenase, see Guccione et al., 2010; Juhnke et al., 2009) and nitrate reductase, reduced methyl or benzyl viologen was utilized as the electron donor, which couples with the active site subunit of each complex that contains the TAT recognition sequence (i.e. TorA, MfrA and NapA, respectively). TMAO and nitrate were able to act as electron acceptors in intact wild-type and tatC/tatC ${ }^{+}$cells but activity was totally lost in the $t a t C$ mutant (Table 1 ). To 
(a) Wild-type periplasm

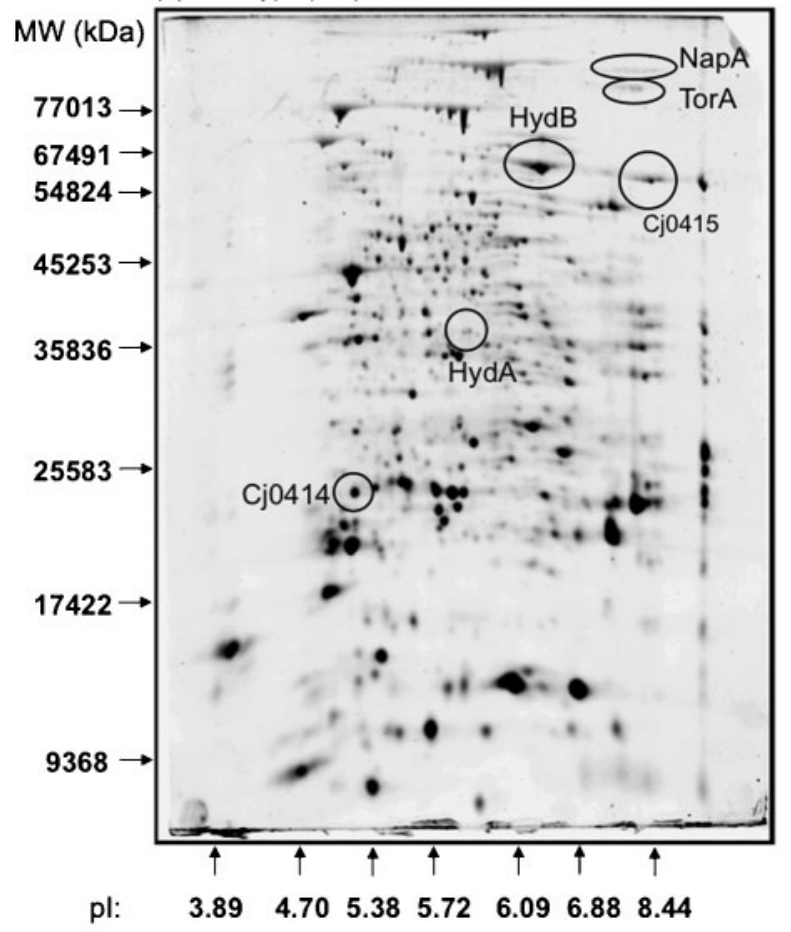

(c) Wild-type periplasm

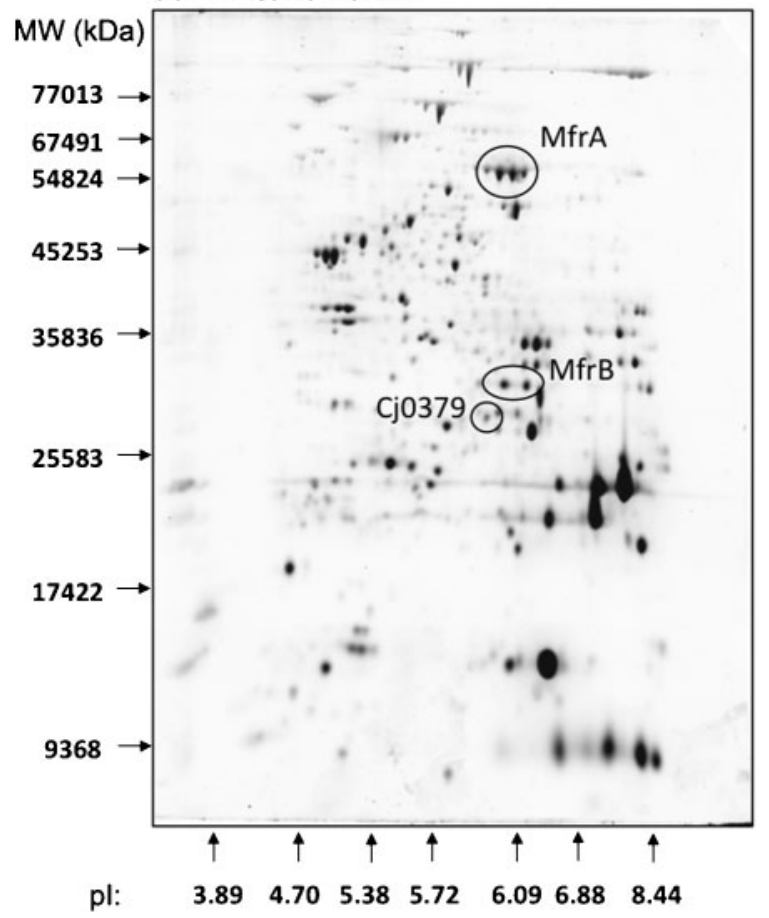

(b) tatC periplasm

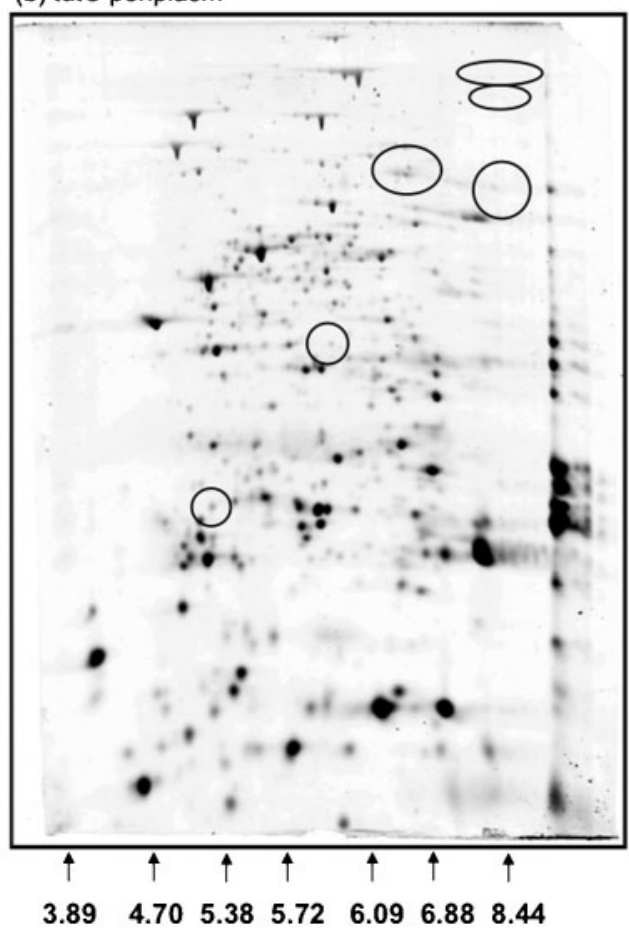

(d) tatC periplasm

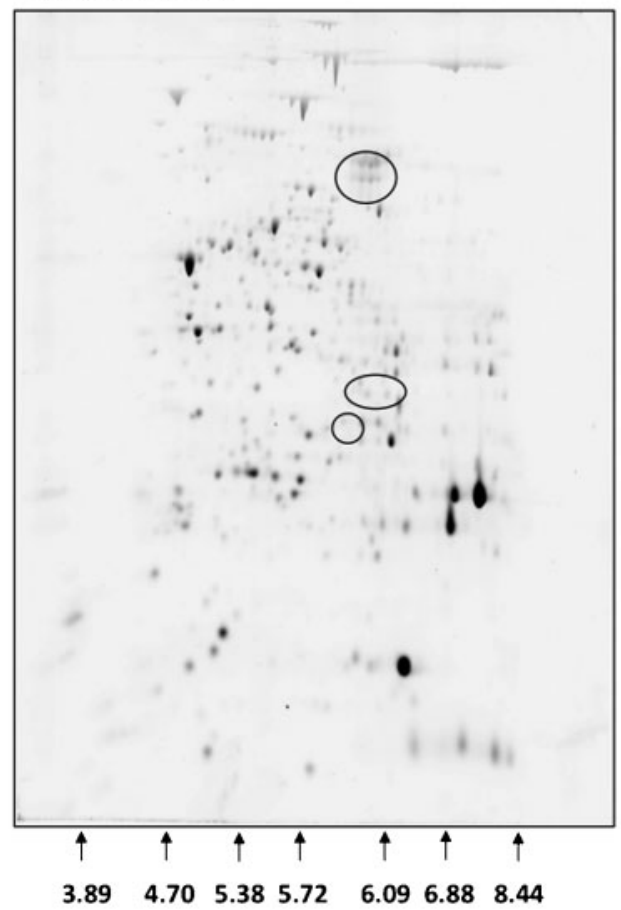

Fig. 2. Proteomic analysis reveals the absence of specific proteins in the periplasm of a tatC mutant. Periplasmic protein (approx. $200 \mu \mathrm{g}$ ) from microaerobically grown wild-type $(\mathrm{a}, \mathrm{c})$ and tat $C$ mutant $(\mathrm{b}, \mathrm{d}$ ) was separated by 2D gel electrophoresis as described in Methods. Selected proteins were identified from spot picks after trypsin digestion and mass spectrometric analysis. Cells were harvested in exponential phase $\left(\mathrm{OD}_{600} 0.6, \sim 7 \mathrm{~h}\right.$ growth $)(\mathrm{a}, \mathrm{b})$ or in stationary phase $\left(\mathrm{OD}_{600} 1.0, \sim 16 \mathrm{~h}\right.$ growth) (c, d). 

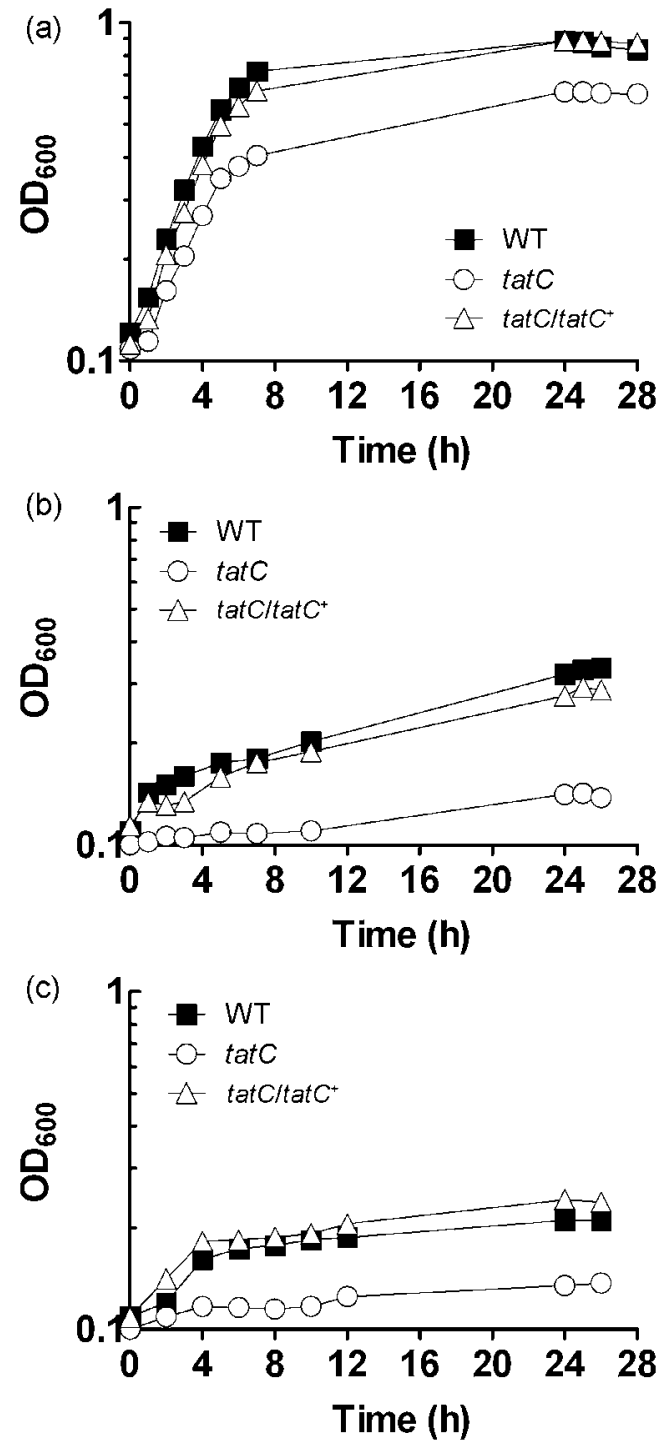

Fig. 3. Microaerobic and oxygen-limited growth of wild-type, tatC and tatC/tatC ${ }^{+}$strains. (a) Microaerobic (oxygen sufficient) growth in $50 \mathrm{ml}$ volumes of un-supplemented BHI-FCS media in $250 \mathrm{ml}$ conical flasks shaken at 180 r.p.m. in a gas atmosphere of $10 \%$ (v/v) oxygen, $5 \%(v / v)$ carbon dioxide and $85 \%(v / v)$ nitrogen. For oxygen-limited growth, BHI-FCS was supplemented with either $20 \mathrm{mM}$ TMAO (b) or $20 \mathrm{mM}$ sodium nitrate (c) contained within almost completely filled unshaken conical flasks. In the absence of an electron acceptor, none of the strains was able to grow under oxygen limitation (data not shown). All data are representative of three independent growth experiments.

specifically assay the periplasmic fumarate reductase activity of the MfrA subunit without interference from the cytoplasmic-facing FrdA, periplasmic extracts were used for viologen-linked assays (Fig. 4a) and immunoblots with anti-Mfr antibodies (Fig. 4b). The results clearly showed the TAT dependence of MfrA activity, the absence of mature $\mathrm{MfrA}$ in the tatC mutant periplasm and the
Table 1. Enzyme activities of predicted TAT substrates in wildtype, tat $\mathrm{C}$ and tat $\mathrm{C} /$ tat $^{+}$strains

The rates shown are the mean $\pm \mathrm{SD}$ of at least three biological replicates.

\begin{tabular}{|lccc|}
\hline \multirow{2}{*}{ Enzyme } & \multicolumn{3}{c|}{ Rate $\left(\mathbf{n m o l ~} \mathbf{~ m i n}^{-\mathbf{1}} \mathbf{~ m g ~ p r o t e i n ~}^{-\mathbf{1}}\right.$ ) } \\
\cline { 2 - 4 } & Wild-type & tatC & tatC/tatC $^{+}$ \\
\hline Sulphite oxidase & $26 \pm 5$ & $<1$ & $24 \pm 7$ \\
TMAO reductase $\dagger$ & $717 \pm 43$ & $<1$ & $705 \pm 18$ \\
Nitrate reductase $\dagger$ & $1572 \pm 453$ & $<1$ & $1482 \pm 384$ \\
Hydrogenase $\ddagger$ & $22 \pm 3$ & $<1$ & $19 \pm 6$ \\
Formate dehydrogenase $\ddagger$ & $166 \pm 4$ & $5 \pm 2$ & $162 \pm 9$ \\
Multicopper oxidase $\$$ & $7 \pm 1$ & $1 \pm 1$ & $5 \pm 2$ \\
& & & \\
\hline
\end{tabular}

${ }^{\star} \mathrm{O}_{2}$ consumption was measured.

$\dagger$ Viologen oxidation was measured.

$\ddagger$ Viologen reduction was measured.

$\$ p$-PD oxidation was measured.

accumulation of the larger unprocessed form of MfrA in the cytoplasm of the tat $C$ mutant.

Hydrogen and formate are key electron donors for C. jejuni that are likely to be used in the host gut environment
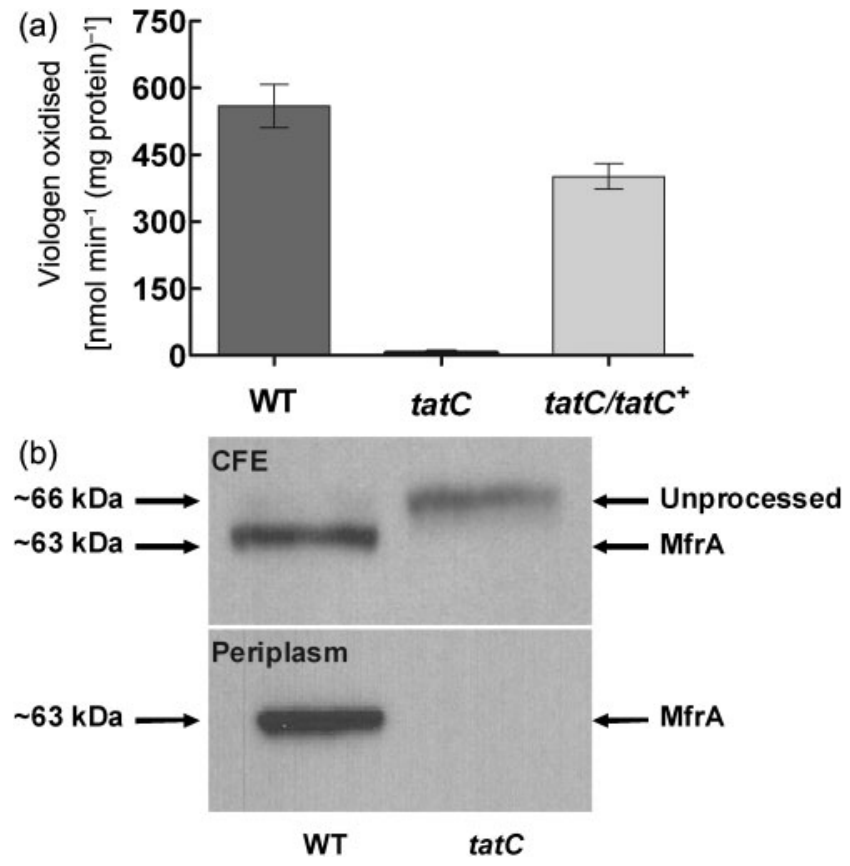

Fig. 4. $M f r A$ is mislocalized in a tat $C$ mutant. (a) Fumarate reductase activity in wild-type, tatC mutant and tatC/tatC ${ }^{+}$ periplasmic fractions. Reduced benzyl viologen was utilized as an artificial electron donor. Data are means \pm SD. (b) Western blot analysis of wild-type and tatC cell-free extracts (top) and periplasm (bottom) with anti-MfrA antibody. Approximately $20 \mu \mathrm{g}$ protein was loaded in each lane. 
(Weerakoon et al., 2009). Hydrogenase enzyme assays performed with intact cells (Table 1) showed a complete lack of activity in the tatC mutant, consistent with the absence of the HydAB subunits in the periplasm (Fig. 2). Similarly, viologen-linked formate dehydrogenase activity was markedly tat $C$-dependent (Table 1 ) and similar results were obtained when formate-dependent oxygen respiration was assayed (data not shown).

It has previously been shown that that the multicopper oxidase (CueO) of C. jejuni, encoded by cj1516, is located in the periplasm (Hall et al., 2008). To determine the dependence of periplasmic localization on the TAT system, the characteristic phenoloxidase activity of this protein was assessed in the wild-type, tatC mutant and complemented strain (Table 1). Although the absolute rates were quite low in these experiments, a clear TAT dependence was observed, with a sevenfold difference in activities between wild-type and mutant cells. The complemented strain showed a restoration in activity to similar levels to that of the wild-type parent.

Cj0414/0415 have been shown to constitute a temperatureregulated gluconate dehydrogenase (GADH) involved in respiration-dependent energy conservation in $C$. jejuni strain 81-176 (Pajaniappan et al., 2008). GADH activity in strain 81-176 was demonstrated by a dye-linked enzyme assay, and by respiration with D-gluconate as the electron donor. In both cases activity was approximately threefold higher after growth at $42{ }^{\circ} \mathrm{C}$ compared with that at $37{ }^{\circ} \mathrm{C}$ (Pajaniappan et al., 2008). We carried out the same assays at both growth temperatures with strain NCTC11168 but could not detect any gluconate-dependent dye reduction or gluconate respiration, yet the protein subunits were present in the wild-type but not tatC mutant periplasm (Fig. 2). In order to further confirm that the predicted TAT signal sequence of cj0414 was functional in protein translocation, we fused this region in-frame with the easily assayable tor $A$ (cj0264c) gene, lacking its own TAT signal sequence, using the pRR plasmid system (Fig. 5a). The fusion plasmid was introduced into a tor A null mutant background so that any viologen-linked TMAO reduction in intact cells must be due to correct periplasmic translocation of the chimeric protein. TMAO reductase activity was indeed present in this strain, was clearly dependent on the presence of the Cj0414 signal sequence (Fig. 5b), but was abolished when the fusion plasmid was introduced into a tatC mutant background (Fig. 5b).

Finally, $\mathrm{NrfH}$ (Cj1358) is a membrane-bound tetra-haem NapC-like cytochrome $c$ and is the sole electron donor to the periplasmic penta-haem nitrite reductase NrfA (Pittman et al., 2007). NrfH is predicted to be membrane-anchored by what could be an uncleaved TAT-like signal sequence with the rest of the protein extending into the periplasm. However, both the TATFIND and TatP programs reject NrfH as a true TAT substrate. To determine if $\mathrm{NrfH}$ assembly into the cytoplasmic membrane is TAT-dependent, its activity as an electron donor to NrfA was measured by comparing rates of succinate-dependent nitrite reduction in intact cell suspensions of wild-type and tat $C$ mutant strains incubated under anaerobic conditions. As controls, nrfH and nrfA null mutants were shown not to reduce nitrite in this assay, as expected (Fig. 6a). As shown in Fig. 6(a, b), the rate of nitrite reduction in the tat $C$ mutant compared to its wild-type parent was very similar, indicating that $\mathrm{NrfH}$ is not a TAT substrate.

\section{A cj0379c mutant has a nitrosative stress phenotype}

While the majority of the functions of the TAT substrates listed in Supplementary Table S2 are known, Cj0379 is the only TAT-translocated molybdoenzyme in C. jejuni whose function remains to be determined. It is homologous to the YedY protein in E. coli, which has some reductase activity with DMSO, tetramethylene sulfoxide (TMSO), L-methionine sulfoxide (MetSO) and TMAO (Loschi et al., 2004). However, the kinetic parameters with all these substrates were very poor. In order to test the possibility that $\mathrm{Cj} 0379$ has a physiological role as an $\mathrm{N}$ - or S-oxide reductase, growth experiments were carried out with wild-type and isogenic cj0379c mutant strains under oxygen-limited conditions with TMAO, DMSO, TMSO, MetSO or methylene sulfoxide (MTSO) as electron acceptors. Growth of both strains on all of these compounds was similar (data not shown) and similar rates of electron-acceptor-dependent oxidation of reduced methyl viologen were found with all these substrates, most likely catalysed by the broad specificity TMAO reductase Cj0264. In addition, no differences in sulphite oxidase, or viologen-linked nitrate or nitrite reductase activity between wild-type and cj0379c strains could be detected (data not shown).

One possible role we considered for Cj0379 was in detoxification. Nitrosative stress caused by various reactive nitrogen species is a major feature of host-pathogen interactions, and $C$. jejuni is already known to use the cytoplasmically located globin Cgb (Elvers et al., 2004) and the periplasmic nitrite reductase NrfA (Pittman et al., 2007) to reduce NO. Nitric oxide in solution has a short half-life and a variety of NO donors and nitrosating agents can be used to apply nitrosative stress to bacterial cells. Disc diffusion assays were employed to determine the response of the $c j 0379 c$ mutant to sodium nitroprusside (SNP), a nitrosating agent that predominantly donates the nitrosonium cation $\left(\mathrm{NO}^{+}\right)$to cellular targets. Fig. $7($ a) shows the mean diameter of SNP inhibition zones of either wild-type, $c j 0379 c$ or torA mutants (an additional control for the specificity of phenotypes observed for the cj0379c mutant). The $c j 0379 c$ mutant was found to have a significantly higher sensitivity $(P=0.008)$ to SNP than the wildtype and the torA strains. The response to a different source of nitrosative stress, an NO releaser (spermine NONOate) was also investigated by disc diffusion assays and similar results were obtained (data not shown). These strains were also tested for sensitivity to superoxide to determine 

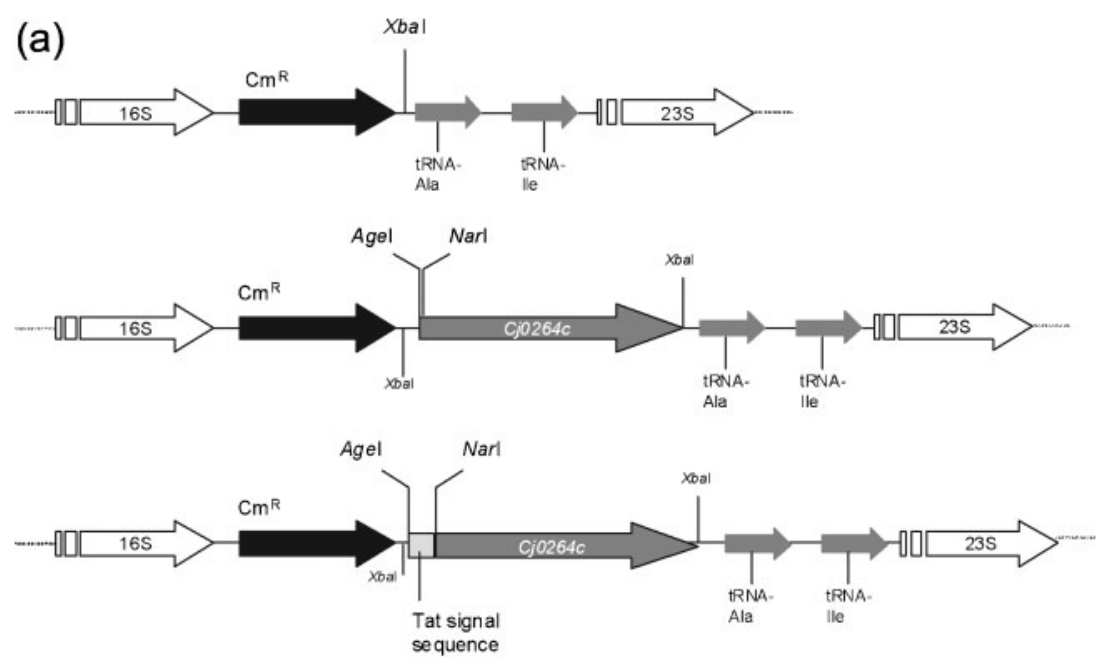

(b)

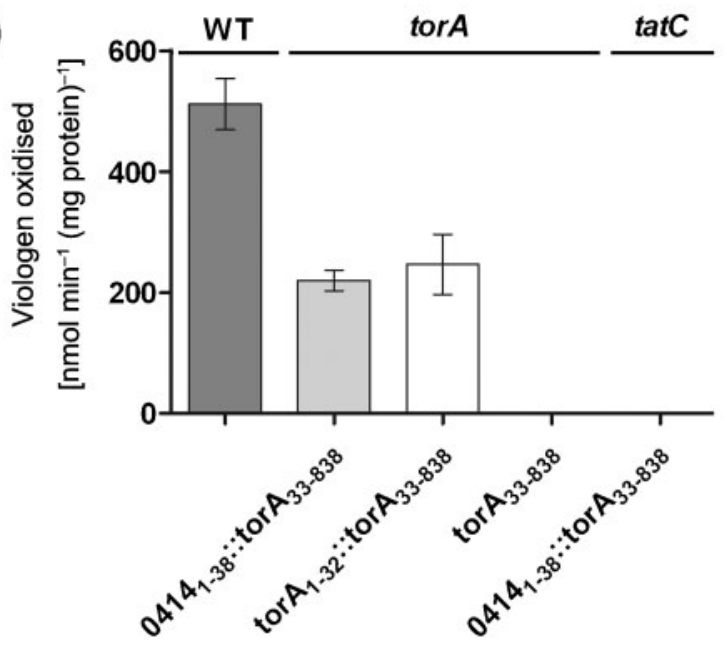

Fig. 5. The Cj0414 TAT signal sequence is able to translocate the TorA reporter protein across the cytoplasmic membrane. (a) Strategy for TAT signal sequence fusion. The torA (cj0264c) gene lacking its own TAT signal sequence was cloned into the $X b a l$ site of the pRRC vector (Karlyshev \& Wren, 2005) generating the plasmid pSJHX. Signal peptides amplified by PCR were digested with Agel and $\mathrm{Narl}$ and cloned into similarly digested $\mathrm{pSJHX}$ to produce in-frame signal peptide-tor $A$ fusions. These fusion plasmids were used to transform C. jejuni $\mathrm{SJH} 100$ carrying an insertionally inactivated tor $A$ gene (Sellars et al., 2002), and the tatC mutant. (b) TMAO reductase activity of wild-type and fusion strains measured using reduced methyl viologen as an artificial electron donor. The subscript numbering following the gene name in the fusion strains corresponds to the amino acid sequence in the wild-type cj0414 and torA genes. The gene fusions were transformed into either the SJH100 torA mutant or the tat $C$ mutant background as indicated. Data shown are means \pm SD from three biological replicates.

whether the phenotype was specific to nitrosative stress or was an indirect effect resulting in general oxidative stress sensitivity. Paraquat (methyl viologen) was used as a superoxide-generating agent in disc diffusion assays; the results showed no significant difference in the diameter of growth-inhibited zones between wild-type and the $c j 0379 c$ mutant (data not shown).

Further experiments were carried out in liquid cultures to examine the effect of SNP-induced nitrosative stress on cell viability. Fig. 7(b) shows a dose-response curve of the viability of wild-type, $c j 0379 c$ and torA strains after a $1 \mathrm{~h}$ exposure to increasing concentrations of SNP. At a concentration of $10 \mathrm{mM}$ SNP, there was a 1-log difference in killing of $c j 0379 c$ compared with the wild-type and torA strains. At $15 \mathrm{mM} \mathrm{SNP}, c j 0379 c$ was greater than 6-logs less viable than wild-type and torA. All strains were completely killed at concentrations above $20 \mathrm{mM}$ SNP. However, SNP can release cyanide in addition to donating $\mathrm{NO}^{+}$ions to cellular targets. Control experiments with up to $20 \mathrm{mM}$ sodium cyanide showed less than a 1-log decrease in viability and no significant difference between the strains (data not shown).
Finally, direct consumption of $\mathrm{NO}$ in anaerobic whole cell suspensions was investigated to determine if the inactivation of $c j 0379 c$ reduced the ability of $C$. jejuni to degrade exogenous $\mathrm{NO}$ added as an aqueous solution. This can be conveniently measured using an NO selective electrode, but often occurs in a complex nonlinear manner (Pittman et al., 2007), as degradation of NO to nitrite and other nitrogen species can proceed both enzymically and by chemical/non-biological routes (Hughes 1999; Watmough et al., 1999). In the experiment shown in Fig. 7(c), the time taken for $50 \%$ of the NO to be degraded when a pulse of NO saturated anaerobic water is injected into the reaction chamber was measured. The NO half-degradation time was increased by about $15 \%$ in cj0379c compared with the wild-type parent strain, and the difference in half-degradation time was shown to be significant $(P=0.035)$ in these experiments. There was also an increase in the average peak-height of the electrode response in the mutant cell suspensions immediately after injection of the NO solution (Fig. 7c), which may also be expected if these cells have a reduced ability to degrade NO, but this was not significant at $P>0.05$. 


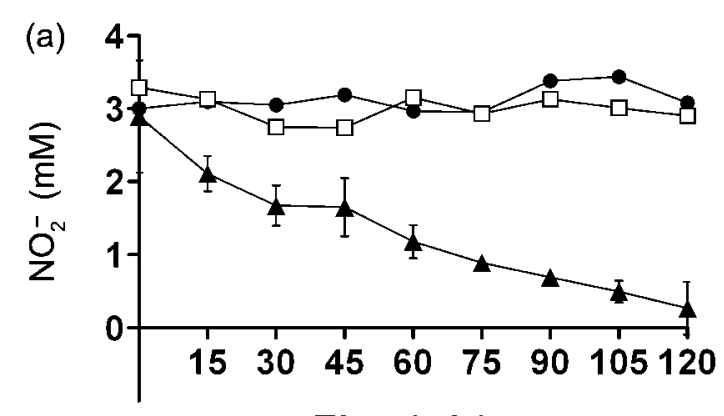

Time (min)

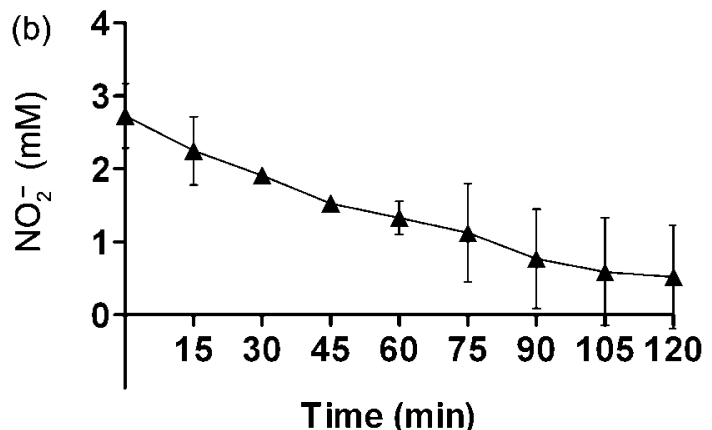

Fig. 6. A C. jejuni tat $C$ mutant retains the ability to utilize nitrite as an electron acceptor. (a) Nitrite utilization in intact wild-type ( $\mathbf{A})$, $n r f A(\bullet)$ and $n r f H(\square)$ mutant cells. (b) Corresponding rate of nitrite utilization in a tat $C$ mutant. Nitrite utilization was used as an indicator of electron transfer from succinate to nitrite, via $\mathrm{NrfH}$. The decrease in nitrite concentration in the supernatant was determined by using the assay described by Pittman et al. (2007) following an initial addition of $3 \mathrm{mM}$ nitrite to a suspension of anaerobic cells $\left(6 \mathrm{mg} \mathrm{ml}^{-1}\right.$ cell protein in each assay, $20 \mathrm{mM}$ succinate as electron donor) in an oxygen electrode. Data shown are means $\pm S D$ of at least two biological replicates.

\section{A cj0379c mutant is defective in chicken colonization}

The effect of disrupting the $c j 0379 c$ gene in colonization of C. jejuni was tested in a chicken model. The cj0379c mutation was introduced into C. jejuni NCTC11168H, a hyper-motile variant previously described by Karlyshev et al. (2002) by the mutagenesis strategy described above using the pcj0379kan plasmid construct. The $c j 0379 \mathrm{cH}$ mutant was confirmed to be motile and to grow at the same rate as the parent strain. The colonization model used has been described previously (Jones et al., 2004). It involved the inoculation of 2-week-old Light Sussex chickens possessing an acquired natural gut flora with the desired strains, and testing the birds over a 7 week period for evidence of colonization. The hyper-motile wild-type strain used was previously adapted for colonization (Jones et al., 2004) and was found to have a high and persistent level of colonization over the course of this study; Fig. 7(d) shows it was detected in $100 \%$ of the birds from the first week of the study through to the 7th week, after which a post-mortem examination showed the birds contained a mean of $2.6 \times 10^{9}$ c.f.u. (g caecal contents) ${ }^{-1}$. Fig. $7(\mathrm{~d})$ also shows that the $c j 0379 \mathrm{cH}$ mutant strain was not detectable by the direct count method throughout the 7-week study, and only $10 \%$ colonization was detected by the enrichment method in the first week which reduced to $5 \%$ in weeks 2 and 3 , and then colonization was undetectable by enrichment for the rest of the study. A post-mortem examination of the caecal contents revealed that the $c j 0379 \mathrm{cH}$ strain was below detectable limits of $<100$ c.f.u. $\mathrm{g}^{-1}$.

\section{The TorD homologue $\mathrm{Cj} 1514$ has a specific role in the biogenesis of formate dehydrogenase, but is not required for TMAO reductase activity}

The sole torD homologue of C. jejuni, cj1514c, is paradoxically located upstream of the formate dehydrogenase operon, fdhABCD (Parkhill et al., 2000; Turner et al., 2004), and overlaps cj1513c, which is a small gene of unknown function predicted to be TAT-transported and translationally coupled to the downstream $f d h A$ gene (see Fig. 8a, b). In order to ascertain whether the $C$. jejuni tor $D$ homologue acts specifically or has a more general chaperone activity, a cj1514c knockout mutant was constructed and assayed (Fig. 8c, d) for its ability to oxidize formate and sulphite, and reduce TMAO and nitrate, the substrates of the four assayable molybdo/tungsto-enzymes in C. jejuni NCTC 11168 (Smart et al., 2009; Taveirne et al., 2009). Both wildtype and $c j 1514 c$ mutant cells were able to catalyse viologendependent nitrate reduction, and respire sulphite at similar rates (Fig. 8d). TMAO reductase activity was actually slightly increased in the mutant strain, possibly indicating a negative effect of Cj1514 on the export or maturation of TorA. However, formate dehydrogenase activity was completely abolished in the $c j 1514 c$ mutant when assayed by either formate-dependent viologen reduction or formate respiration (Fig. 8c). In order to confirm that this phenotype was due to inactivation of $c j 1514 c$ and not any polar effect on the downstream $c j 1513 c$ and $f d h$ operon, a complemented merodiploid strain was generated. Activity in this strain was restored to $\sim 65 \%$ of the wild-type rate in both the formate dehydrogenase assays described above (Fig. 8c). We thus propose that the $c j 1514 c$ gene should be designated $f d h M$ (for formate dehydrogenase maturation).

\section{DISCUSSION}

One of the key features of $C$. jejuni that is essential to understanding its capacity for both host colonization and survival in the environment is the diversity of the electron transport chains that allow continued energy conservation under changing conditions of electron donor and electron acceptor availability. As with other bacteria, the active site subunits of many of the cofactor-containing primary dehydrogenases and terminal reductases are located in the periplasm and are predicted to be translocated by the TAT system (see Fig. 1). In this study we used a tatC knockout mutant to gain experimental evidence for the 
(a)

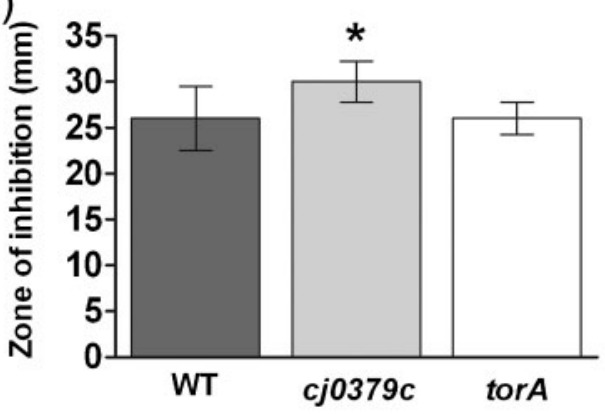

(b)

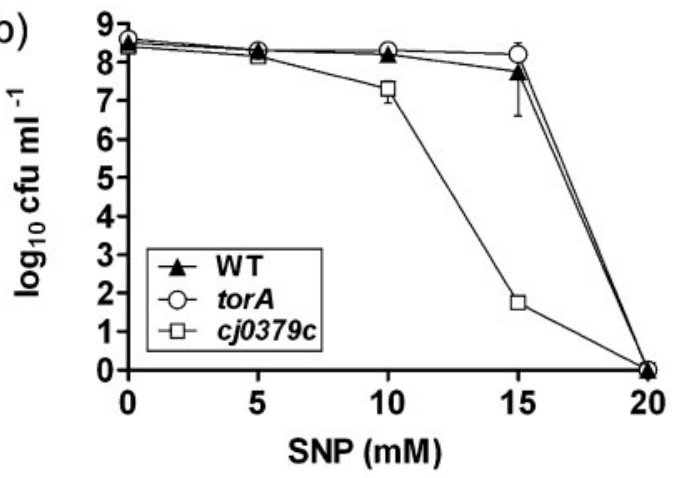

(c)

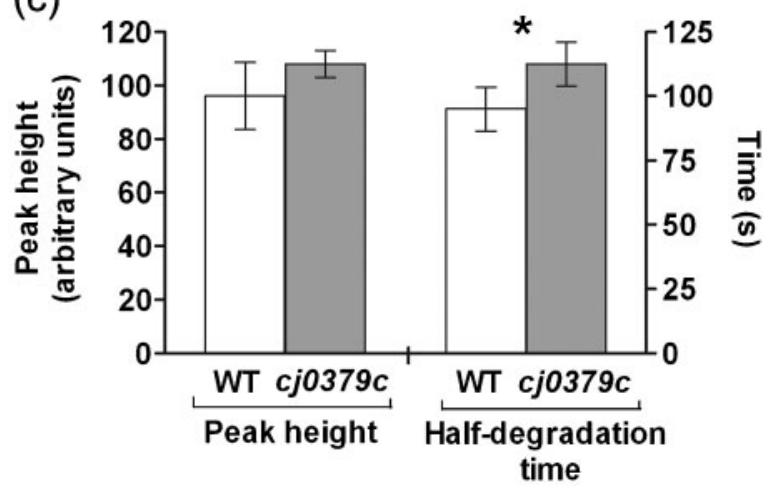

(d)

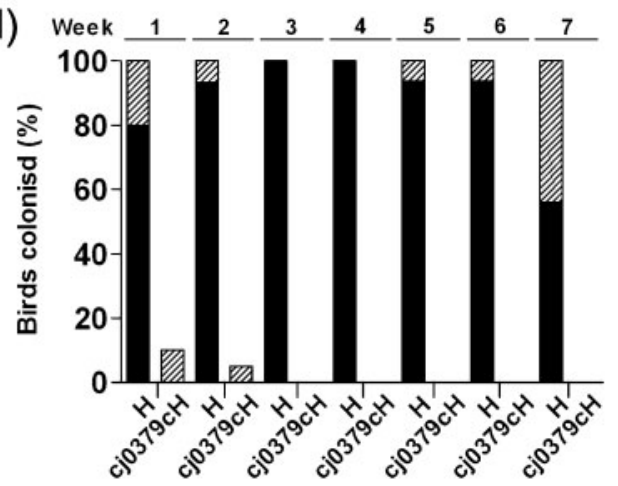

Fig. 7. Nitrosative stress sensitivity and chicken colonization phenotype of a cj0379c mutant. (a) Disc diffusion assays with SNP. Inhibition zones for wild-type, cj0379c and cj0264c mutants were measured (12 replicates) after 2 days microaerobic incubation. The asterisk indicates a significant difference between the wild-type and cj0379c mutant $(P=0.008)$ by Student's $t$-test. Error bars indicate SD. (b) Dose-response curve of SNP killing. Data shown are means \pm SD from three replicate cultures. (c) NO consumption measured by an NO electrode as in Methods. The asterisk indicates a significant difference $(P=0.035)$ in the NO degradation time of the $c j 0379 \mathrm{c}$ mutant compared with the wild-type. The difference in peak height (maximal electrode response after injection of $\mathrm{NO})$ was not significant $(P=0.138)$. Error bars indicate SD. (d) Chicken colonization of $\mathrm{NCTC} 11168 \mathrm{H}$ hyper-motile strain and isogenic cj0379cH mutant. Groups of 243 -week-old Rhode Island Red chickens were inoculated orally at $10^{7}$ c.f.u. and cloacal swabs were taken weekly for direct (filled bars) and enrichment (hashed bars) counts as described in Methods.

TAT dependence of the localization of many of these predicted substrates. An initial proteomics approach using 2D gel separation revealed that some of the key predicted TAT substrates are clearly absent in the tat $C$ periplasm, but variation in protein abundance, the membrane anchoring of some TAT substrates and the fact that not all TAT substrates will necessarily be expressed under the growth conditions or in the media used meant that this approach was unlikely to identify all the proteins of interest. It did, however, highlight the likely co-translocation of the $\mathrm{HydB}$, MfrB and Cj0415 subunits along with the TAT motif containing HydA, MfrA and Cj0414 subunits, respectively, via a probable 'piggy-backing' mechanism (Rodrigue et al., 1999; Berks et al., 2005; Guccione et al., 2010).

The pronounced microaerobic growth defect of the tat $C$ mutant observed here was also previously reported with strains 81116 (van Mourik et al., 2008) and 81-176 (Rajashekara et al., 2009). The most likely explanation for this is disruption of electron flow to oxygen via the cytochrome $b c_{1}$ complex, as the membrane-bound Rieske iron-sulphur subunit is a well predicted TAT substrate and has been reported to be TAT translocated in other bacteria (Bachmann et al., 2006; De Buck et al., 2007). The bioenergetic consequences of a non-functioning $b c_{1}$ complex would be a decreased growth yield, not only as this is a major site of proton-translocation and thus proton-motive force (pmf) generation but also because it feeds electrons to the $c b$-type cytochrome $c$ oxidase which is also proton-translocating (Pitcher \& Watmough, 2004). The only alternative electron transport pathway to oxygen in the tat $C$ mutant is thus via the quinol oxidase CioAB (Jackson et al., 2007) which is not energy conserving, leaving electrogenic primary dehydrogenases which are not TAT substrates as the only mechanism to generate a pmf. There seem to be few examples of these (Fig. 1b) but the unusual flavodoxin-dependent Nuo complex that has been shown to be involved in 2-oxoglutarate respiration (Weerakoon \& Olson, 2008) may become especially important in the tat $C$ mutant. On the other hand, the complete 
(a)

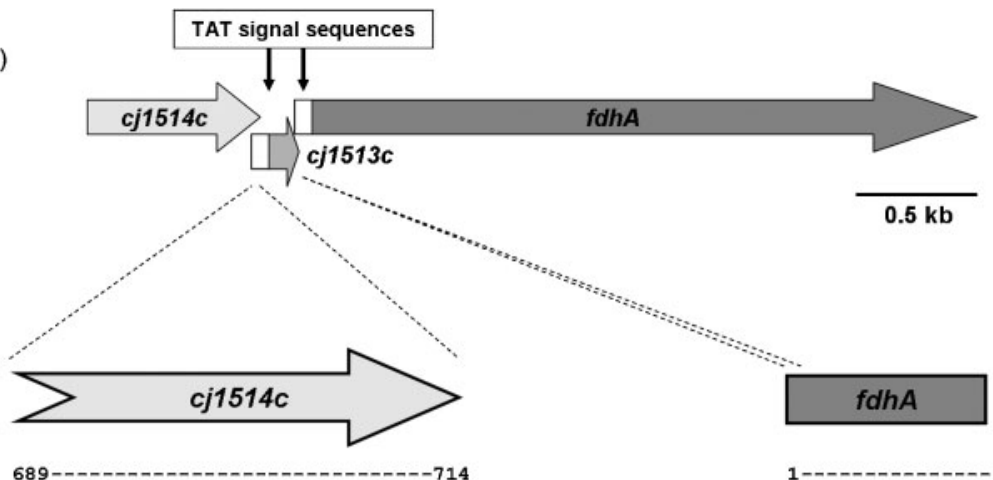

(b) GTGAAAAATCGCAGGGAATTTCTTAA

$\underline{\mathrm{ATG}}$

GTGAAAAATCGCAGGGAATTTCTTA_A_//TTATATAAAGGCTGAGTAA

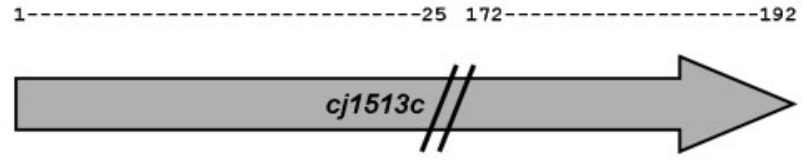

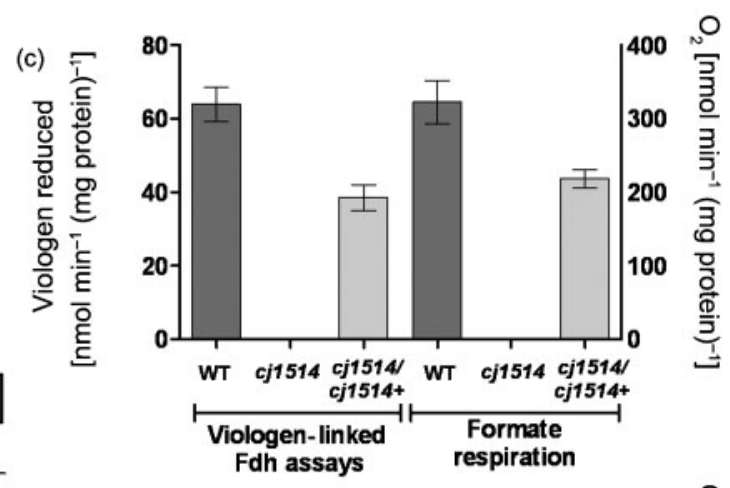

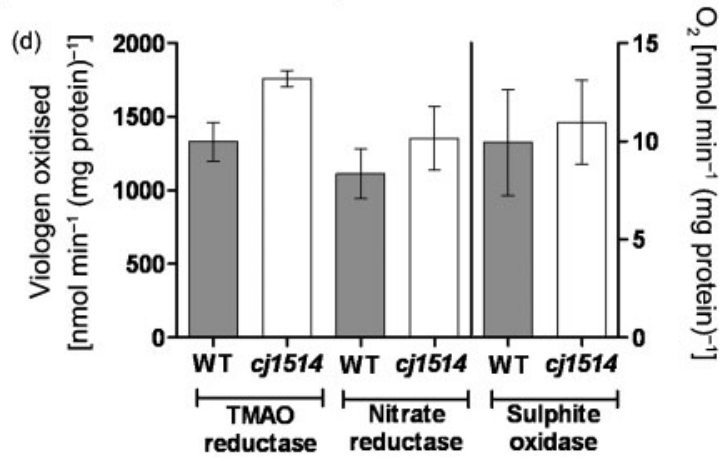

Fig. 8. Cj1514 is required for formate dehydrogenase activity. (a) The arrangement of the genes upstream of $f d h A ; c j 1514 c$ is a tor $D$ homologue and $c j 1513 c$ is a TAT domain protein of unknown function. The positions of the TAT consensus sequence are shown by arrows and white boxes. (b) The sequence overlap between (left) the $3^{\prime}$ end of $c j 1514 c$ and $5^{\prime}$ end of cj1513c; and (right) the $3^{\prime}$ end of $c j 1513 c$ and the $5^{\prime}$ end of $f d h A$. The sequence numbers match the bold and underlined nucleotides. (c) Formate dehydrogenase activity of wild-type, cj1514 and cj1514/cj1514 ${ }^{+}$strains of C. jejuni measured both as viologen-linked activity and formate-dependent oxygen respiration. (d) The activity of the assayable molybdoenzymes in wild-type and cj1514 mutant strains. TMAO reductase and nitrate reductase activity was determined using viologen dyes as artificial electron donors, and sulphite oxidase activity by oxygen uptake measurements. Data shown are means \pm SD of three biological replicates. The slight increase in TMAO reductase activity in the cj1514c mutant is significant at $P<0.05$.

lack of growth of the tatC mutant under oxygen-limited conditions on TMAO or nitrate as electron acceptors is easily explained by the absolute TAT dependence of the respective terminal reductases.

Previous studies of the TAT system in C. jejuni strain 81116 have confirmed that two predicted substrates are actually translocated in a TAT-dependent manner, namely alkaline phosphatase (Cj0145) and nitrate reductase (van Mourik et al., 2008). It should be noted that TATFIND rejects alkaline phosphatase as a TAT substrate, underlining the need for experimental verification of each prediction. Here, we employed multiple enzyme assays to compare catalytic rates in the isogenic set of wild-type, tatC and tatC/tat $C^{+}$ complemented strains to enable verification of most of the additional predicted TAT substrates in strain 11168. The only enzyme that (for unknown reasons) we could not detect activity for in this strain was gluconate dehydrogenase (Cj0414/415), and apart from the 2D gel evidence discussed above, we were able to show by a gene fusion approach that the Cj0414 signal peptide is able to facilitate the transport of a heterologous TAT substrate (Fig. 5). The majority of the TATFIND/TatP predictions were confirmed by the enzyme assay results shown in Table 1 and Figs 4 and 6. However, TATFIND rejects HydA as a TAT substrate, because the twin-arginine motif is more than 35 residues from the $\mathrm{N}$ terminus, yet the assay results in Table 1 (as well as the proteomics in Fig. 2) clearly show it is TAT dependent, as are all periplasmic NiFe uptake hydrogenases (Berks et al., 2003). In some cases, previous studies had shown that some of the proteins we predicated (Supplementary Table S2) were localized to the periplasm, for example the sulphite oxidase catalytic subunit SorA was previously detected in the periplasm of $C$. jejuni by immunoblotting (Myers \& Kelly, 2005), the MfrA subunit was detected on 2D gels and by activity assays and immunoblotting of periplasmic extracts (Guccione et al., 2010) and the multicopper oxidase $\mathrm{CueO}$ by periplasmic enzyme assays (Hall et al., 2008). The data obtained here confirm that their periplasmic location is dependent on the TAT system. In the case of $\mathrm{NrfH}$, which has a convincing twin-arginine motif located at the extreme $\mathrm{N}$ terminus (similar to alkaline phosphatase) but was rejected by TATFIND and TatP, we were able to show by nitrite reduction assays 
that the prediction is correct and that $\mathrm{NrfH}$ is not a TAT substrate. Unfortunately, similar assays based on nitrate reduction could not be used to determine the TAT dependence of NapG and $\mathrm{NapH}$, two proteins involved in electron transport to the active site subunit NapA (Pittman et al., 2007), as NapA is also a TAT substrate.

The most prominent TAT substrate with an unknown function in C. jejuni is the molybdoenzyme encoded by cj0379c. Cj0379 is a member of a distinct group of molybdoenzymes (the YedY family) that contain a simple molybdopterin (MPT) cofactor and which are present in a large number of diverse prokaryotes (Workun et al., 2008). Most of the proteins homologous to Cj0379 are encoded in a two-gene operon, designated yedYZ in E. coli. YedZ is a membrane-bound $b$-type cytochrome that donates electrons to the periplasmic YedY (Brokx et al., 2005), suggesting a similar function for Cj0378 in C. jejuni. Indeed, the crystal structure of YedY (Loschi et al., 2004) shows the active site is similar to that of a reductase, although the overall fold is related to that of sulphite oxidase. All of the key residues in YedY that co-ordinate the MPT cofactor are conserved in Cj0379, including a single, absolutely conserved cysteine at residue 133, which provides an MoS ligand in YedY (Loschi et al., 2004). Although YedY can catalyse reduction of $\mathrm{N}$ - and S-oxides, the kinetics are so poor that these are unlikely to be physiological substrates (Loschi et al., 2004), and no evidence was found in this study that Cj0379 can reduce these electron acceptors. We did gain evidence, however, that the $c j 0379 c$ mutant is more sensitive to killing by nitrosating and NO-releasing agents (with the nitrosating agent SNP producing the greatest effect), and has a decreased capacity to degrade NO. Superoxide sensitivity was the same as the wild-type, indicating that the increased sensitivity to reactive nitrogen species is a specific effect and not due to a general response to oxidative stress. The phenotypic differences we observed were small, but this may be expected in view of the fact that the wild-type and $c j 0379 c$ mutant will both express $\mathrm{Cgb}$ and NrfA - by far the two major contributors to cellular NO defence (Elvers et al., 2004; Pittman et al., 2007). The data imply that Cj0379 may be able to reduce one or more reactive nitrogen species, either NO itself or a reaction product like peroxynitrite $\left(\mathrm{ONOO}^{-}\right)$, but this can only be confirmed by studies with the purified enzyme. Nevertheless, the colonization defect of the mutant would suggest an important role for Cj0379 in vivo, either as part of an NO defence system or because it can reduce some unknown additional electron acceptor that is important for caecal growth.

Most periplasmic redox enzymes with complex cofactors have dedicated REMPs that partly serve to co-ordinate cofactor insertion in the cytoplasm with TAT translocation. In C. jejuni, only two such REMPs are encoded in the genome (Turner et al., 2004), Cj1514 and Cj0785 (NapD). Surprisingly, despite being a member of the TorD family, we found that $\mathrm{Cj} 1514$ is not required for maturation of the TMAO reductase Cj0264, but is essential for the activity of formate dehydrogenase, consistent with the location of the cognate gene upstream of FdhA. Polar effects of the mutation were not responsible for this phenotype as complementation with only the $c j 1514 c$ gene at a distant locus restored formate dehydrogenase activity. In other bacteria, the formate dehydrogenase REMP has yet to be clearly identified, so the use of a TorD homologue in this role is unprecedented. It is proposed that $\mathrm{Cj} 1514$ should be designated FdhM (for maturation). Furthermore, cj1514c has a complex overlapping gene arrangement with a novel small gene $(c j 1513 c)$ that also overlaps FdhA. Cj1513 is composed of a TAT signal sequence with a strongly predicted cleavage site that would give a mature peptide of just 33 residues (Fig. 8). The role of this novel protein is unknown but it seems to be specific to the epsilonproteobacteria. One intriguing possibility is that this protein is somehow related to the likely use of a tungsten-pterin cofactor in the C. jejuni formate dehydrogenase (Smart et al., 2009; Taveirne et al., 2009).

\section{ACKNOWLEDGEMENTS}

This work was supported by a grant from the UK Biotechnology and Biological Sciences Research Council (BBSRC) (no. BB/D008395/1) to D. J.K. for S.J.H., and a CASE studentship to A.H. from the BBSRC in partnership with Don Whitley Scientific Ltd (Shipley, UK). A BBSRC Core Strategic Grant supported the work at the Institute of Food Research; mass spectrometry was performed by Mike Naldrett at the Joint IFR/JIC Proteomic Facility. The authors wish to thank Rob Salmon, Sarah Lucas and John Wells for experimental assistance.

\section{REFERENCES}

Atack, J. M., Harvey, P., Jones, M. A. \& Kelly, D. J. (2008). The Campylobacter jejuni thiol peroxidases Tpx and Bcp both contribute to aerotolerance and peroxide-mediated stress resistance but have distinct substrate specificities. J Bacteriol 190, 5279-5290.

Bachmann, J., Bauer, B., Zwicker, K., Ludwig, B. \& Anderka, O. (2006). The Rieske protein from Paracoccus denitrificans is inserted into the cytoplasmic membrane by the twin-arginine translocase. FEBS J 273, 4817-4830.

Baylis, C. L., McFee, S., Martin, K. W., Humphrey, T. J. \& Betts, R. P. (2000). Comparison of three enrichment media for the isolation of Campylobacter spp from foods. J Appl Microbiol 89, 884-891.

Bendtsen, J. D., Nielsen, H., Widdick, D., Palmer, T. \& Brunak, S. (2005). Prediction of twin-arginine signal peptides. $B M C$ Bioinformatics 6, 167.

Berks, B. C. (1996). A common export pathway for proteins binding complex redox cofactors? Mol Microbiol 22, 393-404.

Berks, B. C., Palmer, T. \& Sargent, F. (2003). The Tat protein translocation pathway and its role in microbial physiology. $A d v$ Microb Physiol 47, 187-254.

Berks, B. C., Palmer, T. \& Sargent, F. (2005). Protein targeting by the bacterial twin-arginine translocation (Tat) pathway. Curr Opin Microbiol 8, 174-181.

Brokx, S. J., Rothery, R. A., Zhang, G., Ng, D. P. \& Weiner, J. H. (2005). Characterization of an Escherichia coli sulfite oxidase homologue reveals the role of a conserved active site cysteine in assembly and function. Biochemistry 44, 10339-10348. 
Bronstein, P., Marrichi, M. \& DeLisa, M. P. (2004). Dissecting the twin-arginine translocation pathway using genome-wide analysis. Res Microbiol 155, 803-810.

Chan, C. S., Chang, L., Rommens, K. L. \& Turner, R. J. (2009). Differential Interactions between Tat-specific redox enzyme peptides and their chaperones. J Bacteriol 191, 2091-2101.

De Buck, E., Vranckx, L., Meyen, E., Maes, L., Vandersmissen, L., Anne, J. \& Lammertyn, E. (2007). The twin-arginine translocation pathway is necessary for correct membrane insertion of the Rieske $\mathrm{Fe} / \mathrm{S}$ protein in Legionella pneumophila. FEBS Lett 581, 259-264.

De Buck, E., Lammertyn, E. \& Anne, J. (2008). The importance of the twin-arginine translocation pathway for bacterial virulence. Trends Microbiol 16, 442-453.

Dilks, K., Rose, R. W., Hartmann, E. \& Pohlschroder, M. (2003). Prokaryotic utilisation of the twin-arginine translocation pathway: a genomic survey. J Bacteriol 185, 1478-1483.

Elvers, K. T., Wu, G., Gilberthorpe, N. J., Poole, R. K. \& Park, S. F. (2004). Role of an inducible single-domain hemoglobin in mediating resistance to nitric oxide and nitrosative stress in Campylobacter jejuni and Campylobacter coli. J Bacteriol 186, 5332-5341.

Gaskin, D. J. H., Van Vliet, A. H. M. \& Pearson, B. M. (2007). The Campylobacter genetic toolbox: development of tractable and generally applicable genetic techniques for Campylobacter jejuni. Zoon Publ Health 54 (Suppl. 1), 101.

Genest, O., Neumann, M., Seduk, F., Stocklein, W., Mejean, V., Leimkuhler, S. \& lobbi-Nivol, C. (2008). Dedicated metallochaperone connects apoenzyme and molybdenum cofactor biosynthesis components. J Biol Chem 283, 21433-21440.

Genest, O., Mejean, V. \& Iobbi-Nivol, C. (2009). Multiple roles of TorD-like chaperones in the biogenesis of molybdoenzymes. FEMS Microbiol Lett 297, 1-9.

Gohlke, U., Pullan, L., McDevitt, C. A., Porcelli, I., de Leeuw, E., Palmer, T., Saibil, H. R. \& Berks, B. C. (2005). The TatA component of the twin-arginine protein transport system forms channel complexes of variable diameter. Proc Natl Acad Sci U S A 102, 10482-10486.

Graubner, W., Schierhorn, A. \& Bruser, T. (2007). DnaK plays a pivotal role in Tat targeting of $\mathrm{CueO}$ and functions beside SlyD as a general Tat signal binding chaperone. J Biol Chem 282, 7116-7124.

Guccione, E., Hitchcock, A., Hall, S. J., Mulholland, F., Shearer, N., van Vliet, A. H. \& Kelly, D. J. (2010). Reduction of fumarate, mesaconate and crotonate by Mfr, a novel oxygen-regulated periplasmic reductase in Campylobacter jejuni. Environ Microbiol 12, 576-591.

Hall, S. J., Hitchcock, A., Butler, C. S. \& Kelly, D. J. (2008). A Multicopper oxidase (Cj1516) and a CopA homologue (Cj1161) are major components of the copper homeostasis system of Campylobacter jejuni. J Bacteriol 190, 8075-8085.

Hendrixson, D. R. \& DiRita, V. J. (2004). Identification of Campylobacter jejuni genes involved in commensal colonization of the chick gastrointestinal tract. Mol Microbiol 52, 471-484.

Hinsley, A. P., Stanley, N. R., Palmer, T. \& Berks, B. C. (2001). A naturally occurring bacterial Tat signal peptide lacking one of the 'invariant' arginine residues of the consensus targeting motif. FEBS Lett 497, 45-49.

Holmes, K., Mulholland, F., Pearson, B. M., Pin, C., McNichollKennedy, J., Ketley, J. M. \& Wells, J. M. (2005). Campylobacter jejuni gene expression in response to iron limitation and the role of Fur. Microbiology 151, 243-257.

Hughes, M. N. (1999). Relationships between nitric oxide, nitroxyl ion, nitrosonium cation and peroxynitrite. Biochim Biophys Acta 1411, 263-272.
Ilbert, M., Mejean, V., Giudici-Orticoni, M. T., Samama, J. P. \& lobbiNivol, C. (2003). Involvement of a mate chaperone (TorD) in the maturation pathway of molybdoenzyme TorA. J Biol Chem 278, 28787-28792.

Ize, B., Porcelli, I., Lucchini, S., Hinton, J. C., Berks, B. C. \& Palmer, T. (2004). Novel phenotypes of Escherichia coli tat mutants revealed by global gene expression and phenotypic analysis. J Biol Chem 279, 47543-47554.

Jack, R. L., Buchanan, G., Dubini, A., Hatzixanthis, K., Palmer, T. \& Sargent, F. (2004). Coordinating assembly and export of complex bacterial proteins. EMBO J 23, 3962-3972.

Jackson, R. J., Elvers, K. T., Lee, L. J., Gidley, M. D., Wainwright, L. M., Lightfoot, J., Park, S. F. \& Poole, R. K. (2007). Oxygen reactivity of both respiratory oxidases in Campylobacter jejuni: the cydAB genes encode a cyanide-resistant, low-affinity oxidase that is not of the cytochrome bd type. J Bacteriol 189, 1604-1615.

Jacobs-Reitsma, W., Lyths, U. \& Wagenaar, J. (2008). Campylobacter in the food supply. In Campylobacter, 3rd edn. Edited by I. Nachamkin, C. M. Szymanski \& M. J. Blaser. Washington, DC: American Society for Microbiology.

Jones, M. A., Marston, K. L., Woodall, C. A., Maskell, D. J., Linton, D., Karlyshev, A. V., Dorrell, N., Wren, B. W. \& Barrow, P. A. (2004). Adaptation of Campylobacter jejuni NCTC11168 to high-level colonization of the avian gastrointestinal tract. Infect Immun 72, 3769-3776.

Joshi, M. V., Mann, S. G., Antelmann, H., Widdick, D. A., Fyans, J. K., Chandra, G., Hutchings, M. I., Toth, I., Hecker, M. \& other authors (2010). The twin arginine protein transport pathway exports multiple virulence proteins in the plant pathogen Streptomyces scabies. Mol Microbiol 77, 252-271.

Juhnke, H. D., Hiltscher, H., Nasiri, H. R., Schwalbe, H. \& Lancaster, C. R. (2009). Production, characterization and determination of the real catalytic properties of the putative 'succinate dehydrogenase' from Wolinella succinogenes. Mol Microbiol 71, 1088-1101.

Karlyshev, A. V. \& Wren, B. W. (2005). Development and application of an insertional system for gene delivery and expression in Campylobacter jejuni. Appl Environ Microbiol 71, 4004-4013.

Karlyshev, A. V., Linton, D., Gregson, N. A. \& Wren, B. W. (2002). A novel paralagous gene family involved in phase-variable flagella mediated motility in Campylobacter jejuni. Microbiology 148, 473480.

Kelly, D. J. (2008). Complexity and versatility in the physiology and metabolism of Campylobacter jejuni. In Campylobacter, 3rd edn. Edited by I. Nachamkin, C. M. Szymanski \& M. J. Blaser. Washington, DC: American Society for Microbiology.

Leon-Kempis Mdel, R., Guccione, E., Mulholland, F., Williamson, M. P. \& Kelly, D. J. (2006). The Campylobacter jejuni PEBla adhesin is an aspartate/glutamate-binding protein of an $\mathrm{ABC}$ transporter essential for microaerobic growth on dicarboxylic amino acids. $\mathrm{Mol}$ Microbiol 60, 1262-1275.

Li, H., Chang, L., Howell, J. M. \& Turner, R. J. (2010). DmsD, a Tat system specific chaperone, interacts with other general chaperones and proteins involved in the molybdenum cofactor biosynthesis. Biochim Biophys Acta 1804, 1301-1309.

Loschi, L., Brokx, S. J., Hills, T. L., Zhang, G., Bertero, M. G., Lovering, A. L., Weiner, J. H. \& Strynadka, N. C. (2004). Structural and biochemical identification of a novel bacterial oxidoreductase. J Biol Chem 279, 50391-50400.

Maillard, J., Spronk, C. A., Buchanan, G., Lyall, V., Richardson, D. J., Palmer, T., Vuister, G. W. \& Sargent, F. (2007). Structural diversity in twin-arginine signal peptide-binding proteins. Proc Natl Acad Sci US A 104, 15641-15646. 
Markwell, M. A., Haas, S. M., Bieber, L. L. \& Tolbert, N. E. (1978). A modification of the Lowry procedure to simplify protein determination in membrane and lipoprotein samples. Anal Biochem 87, 206210.

Mickael, C. S., Lam, P. K., Berberov, E. M., Allan, B., Potter, A. A. \& Koster, W. (2010). Salmonella enterica serovar Enteritidis tatB and tat $C$ mutants are impaired in Caco-2 cell invasion in-vitro and show reduced systemic spread in chickens. Infect Immun 78, 3493 3505.

Myers, J. D. \& Kelly, D. J. (2005). A sulphite respiration system in the chemoheterotrophic human pathogen Campylobacter jejuni. Microbiology 151, 233-242.

Nachamkin, I., Yang, X. H. \& Stern, N. J. (1993). Role of Campylobacter jejuni flagella as colonization factors for three-dayold chicks: analysis with flagellar mutants. Appl Environ Microbiol 59, 1269-1273.

Ochsner, U. A., Snyder, A., Vasil, A. I. \& Vasil, M. L. (2002). Effects of the twin-arginine translocase on secretion of virulence factors, stress response, and pathogenesis. Proc Natl Acad Sci U S A 99, 8312-8317.

Oresnik, I. J., Ladner, C. L. \& Turner, R. J. (2001). Identification of a twin-arginine leader-binding protein. Mol Microbiol 40, 323331.

Pajaniappan, M., Hall, J. E., Cawthraw, S. A., Newell, D. G., Gaynor, E. C., Fields, J. A., Rathbun, K. M., Agee, W. A., Burns, C. M. \& other authors (2008). A temperature-regulated Campylobacter jejuni gluconate dehydrogenase is involved in respiration-dependent energy conservation and chicken colonization. Mol Microbiol 68, 474-491.

Palmer, T., Sargent, F. \& Berks, B. C. (2005). Export of complex cofactor-containing proteins by the bacterial Tat pathway. Trends Microbiol 13, 175-180.

Parkhill, J., Wren, B. W., Mungall, K., Ketley, J. M., Churcher, C. Basham, D., Chillingworth, T., Davies, R. M., Feltwell, T. \& other authors (2000). The genome sequence of the food-borne pathogen Campylobacter jejuni reveals hypervariable sequences. Nature 403, 665-668.

Pitcher, R. S. \& Watmough, N. J. (2004). The bacterial cytochrome $\mathrm{cbb}_{3}$ oxidases. Biochim Biophys Acta 1655, 388-399.

Pittman, M. S., Elvers, K. T., Lee, L., Jones, M. A., Poole, R. K., Park, S. F. \& Kelly, D. J. (2007). Growth of Campylobacter jejuni on nitrate and nitrite: electron transport to NapA and $\mathrm{NrfA}$ via $\mathrm{NrfH}$ and distinct roles for NrfA and the globin $\mathrm{Cgb}$ in protection against nitrosative stress. Mol Microbiol 63, 575-590.

Pommier, J., Mejean, V., Giordano, G. \& lobbi-Nivol, C. (1998). TorD, a cytoplasmic chaperone that interacts with the unfolded trimethylamine N-oxide reductase enzyme (TorA) in Escherichia coli. J Biol Chem 273, 16615-16620.

Rajashekara, G., Drozd, M., Gangaiah, D., Jeon, B., Liu, Z. \& Zhang, Q. (2009). Functional characterization of the twin-arginine translocation system in Campylobacter jejuni. Foodborne Pathog Dis 6, 935945.

Ray, N., Oates, J., Turner, R. J. \& Robinson, C. (2003). DmsD is required for the biogenesis of DMSO reductase in Escherichia coli but not for the interaction of the DmsA signal peptide with the Tat apparatus. FEBS Lett 534, 156-160.

Rodrigue, A., Chanal, A., Beck, K., Muller, M. \& Wu, L. F. (1999). Cotranslocation of a periplasmic enzyme complex by a hitchhiker mechanism through the bacterial tat pathway. J Biol Chem 274, 13223-13228.

Rose, R. W., Bruser, T., Kissinger, J. C. \& Pohlschroder, M. (2002). Adaptation of protein secretion to extremely high-salt conditions by extensive use of the twin-arginine translocation pathway. Mol Microbiol 45, 943-950.

Sambrook, J., Fritsch, E. F. \& Maniatis, T. (1989). Molecular Cloning: a Laboratory Manual, 2nd edn. Cold Spring Harbor, NY: Cold Spring Harbor Laboratory.

Santini, C. L., Ize, B., Chanal, A., Muller, M., Giordano, G. \& Wu, L. F. (1998). A novel sec-independent periplasmic protein translocation pathway in Escherichia coli. EMBO J 17, 101-112.

Sargent, F., Berks, B. C. \& Palmer, T. (2002). Assembly of membranebound respiratory complexes by the Tat protein-transport system. Arch Microbiol 178, 77-84.

Sellars, M. J., Hall, S. J. \& Kelly, D. J. (2002). Growth of Campylobacter jejuni supported by respiration of fumarate, nitrate, nitrite, trimethylamine-N-oxide, or dimethyl sulfoxide requires oxygen. $J$ Bacteriol 184, 4187-4196.

Smart, J. P., Cliff, M. J. \& Kelly, D. J. (2009). A role for tungsten in the biology of Campylobacter jejuni: tungstate stimulates formate dehydrogenase activity and is transported via an ultra-high affinity $\mathrm{ABC}$ system distinct from the molybdate transporter. Mol Microbiol 74, 742-757.

Sommerlad, S. M. \& Hendrixson, D. R. (2007). Analysis of the roles of $\mathrm{FlgP}$ and FlgQ in flagellar motility of Campylobacter jejuni. J Bacteriol 189, 179-186.

Stanley, N. R., Findlay, K., Berks, B. C. \& Palmer, T. (2001). Escherichia coli strains blocked in Tat-dependent protein export exhibit pleiotropic defects in the cell envelope. J Bacteriol 183, 139144.

Stingl, K., Schauer, K., Ecobichon, C., Labigne, A., Lenormand, P., Rousselle, J. C., Namane, A. \& de Reuse, H. (2008). In vivo interactome of Helicobacter pylori urease revealed by tandem affinity purification. Mol Cell Proteomics 7, 2429-2441.

Taveirne, M. E., Sikes, M. L. \& Olson, J. W. (2009). Molybdenum and tungsten in Campylobacter jejuni: their physiological role and identification of separate transporters regulated by a single ModElike protein. Mol Microbiol 74, 758-771.

Thomas, M. T., Shepherd, M., Poole, R. K., van Vliet, A. H. M., Kelly, D. J. \& Pearson, B. M. (2010). Two respiratory enzyme systems in Campylobacter jejuni NCTC 11168 contribute to growth on L-lactate. Environ Microbiol (in press).

Turner, R. J., Papish, A. L. \& Sargent, F. (2004). Sequence analysis of bacterial redox enzyme maturation proteins (REMPs). Can $J$ Microbiol 50, 225-238.

van Mourik, A., Bleumink-Pluym, N. M., van Dijk, L., van Putten, J. P. \& Wosten, M. M. (2008). Functional analysis of a Campylobacter jejuni alkaline phosphatase secreted via the Tat export machinery. Microbiology 154, 584-592.

van Vliet, A. H. M., Wooldridge, K. G. \& Ketley, J. M. (1998). Ironresponsive gene regulation in a Campylobacter jejuni fur mutant. J Bacteriol 180, 5291-5298.

Wagenaar, J. A., Jacobs-Reitsma, W., Hofshagen, M. \& Newell, D. (2008). Poultry colonisation with Campylobacter and its control at the primary production level. In Campylobacter, 3rd edn. Edited by I. Nachamkin, C. M. Szymanski \& M. J. Blaser. Washington, DC: American Society for Microbiology.

Wang, Y. \& Taylor, D. E. (1990). Chloramphenicol resistance in Campylobacter coli: nucleotide sequence, expression, and cloning vector construction. Gene 94, 23-28.

Watmough, N. J., Butland, G., Cheesman, M. R., Moir, J. W., Richardson, D. J. \& Spiro, S. (1999). Nitric oxide in bacteria: synthesis and consumption. Biochim Biophys Acta 1411, 456474 . 
Weerakoon, D. R. \& Olson, J. W. (2008). The Campylobacter jejuni NADH:ubiquinone oxidoreductase (complex I) utilizes flavodoxin rather than NADH. J Bacteriol 190, 915-925.

Weerakoon, D. R., Borden, N. J., Goodson, C. M., Grimes, J. \& Olson, J. W. (2009). The role of respiratory donor enzymes in Campylobacter jejuni host colonization and physiology. Microb Pathog 47, 8-15.

Weingarten, R. A., Grimes, J. L. \& Olson, J. W. (2008). Role of Campylobacter jejuni respiratory oxidases and reductases in host colonization. Appl Environ Microbiol 74, 1367-1375.

Weingarten, R. A., Taveirne, M. E. \& Olson, J. W. (2009). The dualfunctioning fumarate reductase is the sole succinate:quinone reductase in Campylobacter jejuni and is required for full host colonization. J Bacteriol 191, 5293-5300.

Workun, G. J., Moquin, K., Rothery, R. A. \& Weiner, J. H. (2008). Evolutionary persistence of the molybdopyranopterin-containing sulfite oxidase protein fold. Microbiol Mol Biol Rev 72, 228248.

Zhang, J. W., Butland, G., Greenblatt, J. F., Emili, A. \& Zamble, D. B. (2005). A role for SlyD in the Escherichia coli hydrogenase biosynthetic pathway. J Biol Chem 280, 4360-4366.

Edited by: T. Parish 